\title{
HYDROXYAPATITE NANOPARTICLE INJECTABLE HYDROGEL SCAFFOLD TO SUPPORT OSTEOGENIC DIFFERENTIATION OF HUMAN MESENCHYMAL STEM CELLS
}

\author{
A.A. Thorpe ${ }^{1}$, S. Creasey ${ }^{2}$, C. Sammon ${ }^{2}$ and C.L. Le Maitre ${ }^{1 *}$. \\ 'Biomolecular Sciences Research Centre, Sheffield Hallam University, Sheffield, UK. \\ ${ }^{2}$ Materials and Engineering Research Institute, Sheffield Hallam University, UK.
}

\begin{abstract}
Bone loss associated with degenerative disease and trauma is a clinical problem increasing with the aging population. Thus, effective bone augmentation strategies are required; however, many have the disadvantages that they require invasive surgery and often the addition of expensive growth factors to induce osteoblast differentiation. Here, we investigated a Laponite ${ }^{\circledR}$ crosslinked, pNIPAMDMAc copolymer (L-pNIPAM-co-DMAc) hydrogel with hydroxyapatite nanoparticles (HAPna), which can be maintained as a liquid ex vivo, injected via narrowgauge needle into affected bone, followed by in situ gelation to deliver and induce osteogenic differentiation of human mesenchymal stem cells (hMSC). L-pNIPAMco-DMAc hydrogels were synthesised and HAPna added post polymerisation. Commercial hMSCs from one donor (Lonza) were incorporated in liquid hydrogel, the mixture solidified and cultured for up to 6 weeks. Viability of hMSCs was maintained within hydrogel constructs containing $0.5 \mathrm{mg} / \mathrm{mL}$ HAPna. SEM analysis demonstrated matrix deposition in cellular hydrogels which were absent in acellular controls. A significant increase in storage modulus (G') was observed in cellular hydrogels with $0.5 \mathrm{mg} / \mathrm{mL}$ HAPna. Semi-quantitative immunohistochemistry and histological analysis demonstrated that bone differentiation markers and collagen deposition was induced within $48 \mathrm{~h}$, with increased calcium deposition with time. The thermally triggered hydrogel system, described here, was sufficient without the need of additional growth factors or osteogenic media to induce osteogenic differentiation of commercial hMSCs. Preliminary data presented here will be expanded on multiple patient samples to ensure differentiation is seen in these samples. This system could potentially reduce treatment costs and simplify the treatment strategy for orthopaedic repair and regeneration.
\end{abstract}

Keywords: Injectable hydrogel, stem cells, thermally responsive, bone regeneration, hydroxyapatite nanoparticles.

*Address for correspondence:

Christine L Le Maitre

Biomolecular Sciences Research Centre

Sheffield Hallam University' Sheffield, S1 1WB, UK

Telephone number: 01142256163

E-mail: c.lemaitre@shu.ac.uk

\section{Introduction}

Traditionally, the use of bone autografts has been regarded as the gold standard clinical intervention for bone repair; however, this therapeutic strategy is limited by the amount of bone that can be used and poses clinical risk in terms of increased operative blood loss and donor-site morbidity (Goulet et al., 1997; Sen and Miclau, 2007). Consequently, a considerable amount of research has been undertaken which aims to develop effective regenerative strategies leading to bone augmentation (Kraus and Kirker-Head, 2006; Mistry and Mikos, 2005). One group of potential biomaterials are hydrogels which are three-dimensional, insoluble, cross-linked, hydrophilic polymeric networks (Geckil et al., 2010) that can potentially be used to deliver cells with regenerative capacity and provide a scaffold to facilitate cell growth, infiltration and differentiation (Benoit et al., 2008; Park et al., 2007). Hydrogels are not generally considered as the material of choice for large bone defects, due to their weak mechanical properties; however, when taking a tissue engineered approach combining the use of cells, biological factors and scaffolds, they offer significant promise. In particular, temperature sensitive hydrogels are attractive since they can be applied as a liquid and gel in situ (Buwalda et al., 2014). An ideal hydrogel would be one which has a low viscosity to deliver cells and/or biological molecules, by minimally invasive injection, and fill micro and macro fractures followed by in situ gelation, assisting in the natural repair and regeneration of bone matrix. Such a material would be of particular use for osteoporosis, nonunion fracture, artificial joint fixation and augmenting bone around dental implants or for treatment of bone defects in patients with periodontal disease. However, to date, the majority of developed hydrogel systems are not fully reacted in the liquid state and thus pose a significant safety risk to surrounding tissues and added cells during delivery, representing a significant challenge in the development of hydrogels for tissue engineering from concept to clinical application (Shin et al., 2003).

Mesenchymal stem cells (MSC) are potentially the most attractive cell choice for bone regeneration since they can be extracted from a variety of adult tissues (Sakaguchi et $a l ., 2005)$, they have proliferative capacity and thus can be easily cultured and expanded ex vivo, they host the ability to differentiate into multiple cell lineages (Jiang et al., 2002) and finally they also avoid the ethical issues surrounding the use of embryonic stem cells. Recent studies have suggested that the source of MSCs are critical to the clinical 
outcome with improved osteogenic differentiation potential in bone marrow derived MSCs in comparison to synovial membrane and adipose tissue derived MSCs (Sakaguchi et al., 2005; Yoshimura et al., 2007). Rational design of biomaterial scaffolds to promote osteogenic differentiation of MSCs, should aim to create a cellular microenvironment that mimics the natural bone architecture and extracellular matrix (ECM) and thus provides the necessary biological, chemical and physical cues (Owen and Shoichet, 2010). Regenerating the complex nanostructure of bone, comprising of nanocrystals of carbonated apatite embedded within a rich collagenous fibrous matrix, has been a significant challenge for hydrogel based scaffolds due to poor mineralisation following implantation (Gkioni et al., 2010). However, bioactivity of hydrogels can be improved by the addition of ceramic phases, such as hydroxyapatite (HAP), which is the inorganic component of bone and constitutes $60 \%$ of native bone ECM (Weiner and Traub, 1992). Synthetic HAP: $\left(\mathrm{CA}_{10}\left(\mathrm{PO}_{4}\right)(\mathrm{OH})_{2}\right)$, has been extensively studied as a supplementary addition to hydrogel scaffolds for bone regeneration, it has been shown to hold significant osteoconductive properties (Dhivya et al., 2015; Isikli et al., 2012; Na et al., 2007, Venugopal et al., 2010; Zhao et al., 2006) and is commonly used for coating of prosthetic joints to aid bone fixation (Furlong and Osborn, 1991; Nilsson et al., 1999). Furthermore, dispersed mineral within biomaterial scaffolds has been shown to enhance mechanical properties (Sinha et al., 2007), provide nucleation sites for further HAP deposition, as well as providing critical cellular anchoring points, which not only enable integration with surrounding bone tissue, but have also been shown to regulate the fate of cellular differentiation (Kim et al., 2007; Rea et al., 2004; Trappmann et al., 2012; Zhao et al., 2006).

A variety of injectable hydrogel scaffolds for tissue regeneration have been reported (D'Este and Eglin, 2013); however, many systems require co-injection with cross linking agents (Halacheva et al., 2014; Lally et al., 2007; Saunders et al., 2007; Shin et al., 2003) which can result in toxicity to the delivered cells as well as the surrounding tissues during injection. Other systems are too viscous for injection through fine-bore needles, which may damage the target site and limit the potential of clinical applications (Michalek et al., 2010; Nassr et al., 2009). Similar pNIPAM/HAP hydrogels for bone repair have been reported; however, the viability of cells incorporated prior to gelation has not always been assessed (Couto et al., 2009) or the use of growth factors has been necessary to induce osteogenesis (Kim et al., 2007; Kim et al., 2011; Liao et al., 2011; Martínez-Sanz et al., 2011; $\mathrm{Na}$ et al., 2007) - thus adding both complexity and cost to the treatment strategy if these approaches were to be used clinically. Wei et al. (2009) reported a cytocompatible pNIPAM grafted HA surface material which supported mineralisation; however, a surface material alone is insufficient to act as a three dimensional cell delivery carrier capable of filling complex tissue cavities in vivo.

Despite substantial advances in the development of hydrogels as regenerative delivery scaffolds for bone augmentation, the ideal load bearing hydrogel that is feasible in terms of clinical application and meets all requirements including: biocompatibility, bioactivity and injectability, without the need for additional osteogenic inducing factors, is yet to be produced. We have previously reported the development of a synthetic hydrogel delivery system which exploits the thermal phase transition of pNIPAM and its ability to form electrostatic interactions with Laponite ${ }^{\circledR}$ surfaces (Boyes et al., 2012a; Boyes et al., 2012b). Laponite ${ }^{\circledR}$ is a synthetic smectite clay with a well-defined structural chemical composition, commonly used in household paper and polymer products. It has $\mathrm{Mg}^{2+}$ $\mathrm{Li}^{+}$cations in the octahedral sites, with $\mathrm{Na}^{+}$cations within the interlayer space. The idealised formula for Laponite is $\mathrm{Na}_{0.7}\left[\mathrm{Mg}_{5.5} \mathrm{Li}_{0.4} \mathrm{Si}_{8} \mathrm{O}_{20}(\mathrm{OH})_{4}\right]$, and the platelets are typically $\sim 30 \mathrm{~nm}$ in diameter with a thickness of $0.92 \mathrm{~nm}$ (Willenbacher, 1996). The polymerisation is carried out using azobisisobutyronitrile (AIBN), which undergoes thermal dissociation at temperatures above which pNIPAM will polymerise in a hydrophobic, globule conformation. This results in polymerisation and chain propagation close to the Laponite ${ }^{\circledR}$ surface, where the polymer/Laponite ${ }^{\circledR}$ particles exist as discrete entities in a stable low viscosity colloidal suspension. This unique colloidal system remains stable, provided the pNIPAM chains are maintained at temperatures that ensure they remain in their globule conformation. Upon cooling, the pNIPAM chains transform from the globule to the coil conformation, the polymer chains extend outwards forming bridging interactions with neighbouring clay platelets and entanglements with adjacent uncoiling polymer chains. The combination of NIPAM with a second monomer DMAc prior to polymerisation results in a crosslinked, 3-dimensional hydrated pNIPAM-DMAc statistical copolymer network which gels upon cooling below $37.1 \pm 0.16^{\circ} \mathrm{C}$ and does not re-liquefy at elevated temperatures. The hydrogel delivery system developed enables the incorporation of cells and injection whilst in the liquid state via small-bore needles, prior to them forming hydrogels in situ without the use of any additional, potentially toxic, reactive agents (Boyes et al., 2012a; Boyes et al., 2012b; Thorpe et al., 2016). We have previously demonstrated, through cell viability studies, that cells could survive, adhere to the hydrogel surface, migrate through the hydrogel and deposit matrix (Boyes et al., 2012b) and recently we have shown the basic hydrogel system promotes MSC differentiation towards nucleus pulposus cells (Thorpe et al., 2016). The aim of this study, was to test the hypothesis that an injectable Laponite ${ }^{\circledR}$ crosslinked, pNIPAM-DMAc copolymer (L-pNIPAM-co-DMAc) hydrogel delivery system, loaded with hydroxyapatite nanoparticles (HAPna), would be structurally sufficient alone to deliver and induce osteogenic differentiation of hMSCs without the need for additional osteogenic inducing factors. Here, we added hMSCs into a thermally responsive hydrogel system, containing HAPna which can be maintained as a liquid prior to gelation at $<37.1 \pm 0.16{ }^{\circ} \mathrm{C}$. The relative simplicity and clinical convenience of such a method could provide an effective and minimally-invasive treatment platform for regeneration of bone in a variety of applications. 


\section{Materials and Methods}

\section{Hydrogel synthesis}

An exfoliated suspension of Laponite ${ }^{\circledR}$ clay nanoparticles (25-30 nm diameter, $<1 \mathrm{~nm}$ thickness) (BYK Additives Ltd, Cheshire UK) was prepared by vigorous stirring of Laponite $^{\circledR}(0.1 \mathrm{~g})$ in deionised $\mathrm{H}_{2} 0(18 \mathrm{~m} \Omega)(9.0 \mathrm{~mL})$ for $24 \mathrm{~h}$. N-isopropylacrylamide $99 \%$ (NIPAM) (0.783 g) (Sigma, Poole, UK), N, N' -dimethylacrylamide (DMAc) (0.117 g) (Sigma, Gillingham, UK) and 2-2'-azobisisobutyronitrile (AIBN) (9 mg) (Sigma, Poole, UK) were added to the suspension and stirred for $1 \mathrm{~h}$. After passing the suspension through a 5-8 $\mu \mathrm{m}$ pore filter paper, polymerisation was initiated by heating to $80{ }^{\circ} \mathrm{C}$ and the reagents were allowed to react for $24 \mathrm{~h}$. It was observed that after heating the monomeric suspension to $80{ }^{\circ} \mathrm{C}$, the transparent liquid transforms to a milky suspension. Following $24 \mathrm{~h}$ the hydrogel suspension, a statistical copolymer with a composition of $1 \%$ Laponite, $7.83 \%$ NIPAM, $1.17 \%$ DMAc and $90 \%$ water (by weight), (MW of resulting hydrogel: $750 \mathrm{kDa}$ ) (Boyes et al., 2012a; Boyes et al., 2012b; Thorpe et al., 2016), was cooled to $50^{\circ} \mathrm{C}$ and hydroxyapatite nanoparticles (HAPna) $(<200 \mathrm{~nm})$ (Sigma, Poole UK) were homogenously mixed into the liquid hydrogel suspension (viscosity at $54{ }^{\circ} \mathrm{C}: 0.97 \mathrm{MPa} / \mathrm{s}$ ) at either $0.5 \mathrm{mg} / \mathrm{mL}$ or $1.0 \mathrm{mg} / \mathrm{mL}$. The hydrogel/HAPna suspension was cooled to $38-39{ }^{\circ} \mathrm{C}$ prior to cell incorporation. Further cooling of the polymeric suspension to $37^{\circ} \mathrm{C}$, i.e. below the gelation temperature of $37.1 \pm 0.16{ }^{\circ} \mathrm{C}$, resulted in a solidified hydrogel (supplementary video 1, available from the ecmjournal. org website page for this paper). The absence of unreacted NIPAM in the system was confirmed using differential scanning calorimetry (DSC).

\section{Material characterisation}

\section{Dynamic mechanical analysis (DMA)}

DMA was performed on no cell control hydrogel samples, without culture, in triplicate using a PerkinElmer DMA8000 model in confined compression mode at $25^{\circ} \mathrm{C}$, applying a sinusoidal force with a $0.02 \mathrm{~mm}$ displacement from 0.63 to $10 \mathrm{~Hz}$. Liquid L-pNIPAM-co-DMAc hydrogel was prepared, solidified and stored for $2 \mathrm{~h}$ at room temperature in an air-lock sealed bag; following this a circular biopsy punch $(5 \mathrm{~mm}$ i.d.) was used to remove cylindrical samples from the solid hydrogel. All sample dimensions were confirmed using digital callipers prior to measurement.

\section{Gelation Temperature}

Liquid L-pNIPAM-co-DMAc hydrogel suspension with $0.5 \mathrm{mg} / \mathrm{mL}$ HAPna was synthesised and allowed to cool to room temperature. A digital calibrated thermometer was used to measure the temperature at which gelation of the hydrogel was initiated. Six replicate measurements were taken from 3 separately prepared hydrogel batches (Table $1)$.

Expansion and incorporation of human mesenchymal stem cells in hydrogels

Commercial bone marrow derived human adult mesenchymal stem cells (hMSCs) extracted from a 38 y old donor (Lonza, Slough, UK) were cultured in DMEM media (Life Technologies, Paisley, UK), supplemented with heat inactivated foetal calf serum (FCS) $(10 \% \mathrm{v} / \mathrm{v})$ (Life Technologies, Paisley, UK), Penicillin (100 U/mL) (Life Technologies Paisley, UK), Streptomycin $(100 \mu \mathrm{g} /$ $\mathrm{mL}$ ) (Life Technologies Paisley, UK), amphotericin (250 ng/mL) (Sigma, Poole UK), glutamine (2 mM) (Life Technologies, Paisley, UK) and ascorbic acid (10 $\mu \mathrm{g} / \mathrm{mL})$ (Sigma, Poole, UK) (complete cell culture media). MSCs were expanded in monolayer culture to passage 9 to ensure sufficient cells were available. Cell seeding solutions were prepared at a density of $1 \times 10^{6}$ cells $/ \mathrm{mL}$, homogenously mixed with the L-pNIPAM-co-DMAc hydrogel suspension $\left(38-39{ }^{\circ} \mathrm{C}\right)$ containing either 0.5 or $1.0 \mathrm{mg} / \mathrm{mL}$ HAPna (Sigma, Poole, UK) and $300 \mu \mathrm{L}$ added into the middle wells of a sterile 48 -well culture plate by 26 -gauge needle injection (Becton Dickinson, Plymouth, UK), leaving the outer wells void of hydrogel. Phosphate buffered saline (PBS) $(300 \mu \mathrm{L})$ (Life Technologies, Paisley, UK) was pipetted into all outer wells of the 48-well plates to prevent drying of hydrogel constructs. $300 \mu \mathrm{L}$ of L-pNIPAM-coDMAc hydrogel suspension, without cells, containing either 0.5 or $1.0 \mathrm{mg} / \mathrm{mL}$ HAPna were also added into wells of a sterile 48 -well culture plate, by 26 -gauge needle injection, to serve as acellular controls. All acellular and hMSC hydrogel scaffolds were cultured in complete cell culture media (as described above) by careful overlay of $1.0 \mathrm{~mL}$ of medium per construct, incubated at $37^{\circ} \mathrm{C}$, $5 \% \mathrm{CO}_{2}$ and maintained in culture for up to 6 weeks. Media were collected and replaced every 2-3 d. Samples were removed after 48 h, 1, 2, 4 and 6 weeks for analysis of cell viability, scanning electron microscopy (SEM), histological assessment of matrix deposition and hMSC differentiation analysis using immunohistochemistry (IHC). Additional samples were also extracted after 4 and 6 weeks to assess the mechanical properties using dynamic mechanical analysis (DMA). All experimental procedures were repeated at least 3 times.

\section{Cytospins}

IHC was performed on hMSCs taken from monolayer culture prior to hydrogel encapsulation to serve as time zero controls. Monolayer cells were trypsinised and cells were fixed in paraformaldehyde/PBS (4 \% w/v) (Sigma, Poole, UK) for $20 \mathrm{~min}$, spun at $300 \times g$ for $5 \mathrm{~min}$ to form a cell pellet and resuspended in PBS to a cell density of 300 cells $/ \mu \mathrm{L} .100 \mu \mathrm{L}$ of cell suspension was then cytospun, formed by centrifugation at $1000 \mathrm{rpm}$ for $3 \mathrm{~min}$ (Shandon Cytospin 3, Thermo Scientific, Loughborough UK). Slides were subsequently air-dried and stored at $4{ }^{\circ} \mathrm{C}$ until required for IHC analysis.

\section{Cytocompatibility assessment of hydroxyapatite hydrogel scaffolds}

The metabolic cell activity of hMSCs incorporated into solidified L-pNIPAM-co-DMAc hydrogels containing either $0,0.5$ or $1.0 \mathrm{mg} / \mathrm{mL}$ HAPna at a density of $1 \times 10^{6}$ cells $/ \mathrm{mL}$ were assessed using Alamar Blue assay (Life Technologies, Paisley, UK) in normal complete media following $0,1,2,3$, and $7 \mathrm{~d}$ using the manufacturers protocol. The fluorescence was recorded 
Table 1. Gelation temperature of Liquid L-pNIPAM-co-DMAc hydrogel suspension with $0.5 \mathrm{mg} / \mathrm{mL}$ HAPna, determined using a digital calibrated thermometer.

\begin{tabular}{|c|c|c|}
\hline $\begin{array}{c}\text { L-pNIPAM-co-DMAc } \\
\text { Batch 1 }\left({ }^{\circ} \mathbf{C}\right)\end{array}$ & $\begin{array}{c}\text { L-pNIPAM-co-DMAc } \\
\text { Batch 2 }\left({ }^{\circ} \mathbf{C}\right)\end{array}$ & $\begin{array}{c}\text { L-pNIPAM-co-DMAc } \\
\text { Batch 3 }\left({ }^{\circ} \mathbf{C}\right)\end{array}$ \\
\hline 37.2 & 37.4 & 36.8 \\
\hline 36.9 & 37.1 & 37.1 \\
\hline 37.3 & 37.4 & 37.3 \\
\hline 37.1 & 37.3 & 37.1 \\
\hline 37.0 & 37.0 & 37.2 \\
\hline 37.3 & 37.2 & 37.0 \\
\hline
\end{tabular}

Table 2. Immunohistochemistry Reagents.

\begin{tabular}{|c|c|c|c|c|c|}
\hline Primary antibody & Clonality & Optimal Dilution & Antigen Retrieval & Blocking Serum & Secondary Antibody \\
\hline Runx2 & Mouse monoclonal & $1: 200$ & NAR & Rabbit & Rabbit anti-mouse \\
\hline Collagen I & Mouse Monoclonal & $1: 200$ & EAR & Rabbit & Rabbit anti-mouse \\
\hline Collagen II & Mouse Monoclonal & $1: 100$ & NAR & Rabbit & Rabbit anti-mouse \\
\hline Collagen X & Mouse Monoclonal & $1: 400$ & EAR & Rabbit & Rabbit anti-mouse \\
\hline Osteopontin & Mouse Monoclonal & $1: 400$ & NAR & Rabbit & Rabbit anti-mouse \\
\hline Osteocalcin & Mouse Monoclonal & $1: 400$ & EAR & Rabbit & Rabbit anti-mouse \\
\hline Aggrecan & Mouse Monoclonal & $1: 200$ & NAR & Rabbit & Rabbit anti-mouse \\
\hline
\end{tabular}

Target antibodies used for IHC (abcam), their optimal concentrations and antigen retrieval methods. No antigen retrieval (NAR), enzyme induced antigen retrieval (EAR). Full method instructions detailed in Materials and Methods section.

using a fluorescence microplate reader (CLARIOstar ${ }^{\circledR}$ is BMG LABTECH) fluorescence excitation wavelength of $590 \mathrm{~nm}$. Relative fluorescence units were recorded and normalised to acellular control hydrogels as an indication of cytotoxicity/proliferation.

\section{Dynamic mechanical analysis}

Acellular and hMSC L-pNIPAM-co-DMAc hydrogels, cultured in MSC medium, containing either $0.5 \mathrm{mg} / \mathrm{mL}$ or $1.0 \mathrm{mg} / \mathrm{mL}$ HAPna were characterised for their mechanical properties after 4 and 6 weeks in culture. Replicate samples were removed from culture, blotted and their mechanical properties characterised by DMA. Samples were extracted using a $5 \mathrm{~mm}$ circumference circular biopsy punch, all sample heights were measured and recorded using digital callipers prior to measurement. Triplicate samples were analysed using a PerkinElmer DMA8000 model under confined compression mode at $25^{\circ} \mathrm{C}$, applying a sinusoidal force with a $0.02 \mathrm{~mm}$ displacement at frequencies between $1-10 \mathrm{~Hz}$.

\section{Hydration degree}

To evaluate the hydration degree of the hMSC and acellular L-pNIPAM-co-DMAc hydrogel scaffolds with 0.5 or $1.0 \mathrm{mg} / \mathrm{mL}$ HAPna, samples were extracted from culture in triplicate following $48 \mathrm{~h}, 1,2,4$ and 6 weeks and the wet weight $\left(M_{o}\right)$ of the samples was measured. Samples were then lyophilised for $8 \mathrm{~h}$ to obtain the dry weight $\left(M_{t}\right)$. The hydration degrees of the hMSC and acellular hydrogel scaffolds were calculated using the following equation:

$$
\text { Hydration degree }=\frac{(M o-M t)}{M o} \times 100
$$

\section{Scanning electron microscopy (SEM)}

Samples were removed from culture after 48 h, 1, 2, 4 and 6 weeks, frozen at $-80^{\circ} \mathrm{C}$ and subsequently freeze dried using a FD-1A-50 Freeze Drier set to $-53^{\circ} \mathrm{C}, 3.8 \times 10^{-4} \mathrm{mbar}$ for $8 \mathrm{~h}$. The sample was then fractured to expose the interior surface morphology attached onto an aluminium stub and then using a Quorum Technology 150 Q TES system coated with either gold $(10 \mu \mathrm{A}$ sputter current for $180 \mathrm{~s}$ with a 2.7 tooling factor) for imaging or with $15 \mathrm{~nm}$ carbon for energy dispersive X-ray (EDX) analysis.

The fracture surfaces were examined using a FEI NOVA nanoSEM 200 scanning electron microscope (SEM). Secondary electron (SE) images were obtained using accelerating voltage $5 \mathrm{kV}$ at various magnifications ranging from $1,000 \times$ to $40,000 \times$. Images were captured and pore sizes $(\mu \mathrm{m})$ measured using the Capture Pro OEM v8.0 software (Media Cybernetics, Buckinghamshire, UK) with 200 pores selected at random from 10 separate images for each given time point.

The SEM was equipped with an Oxford Instruments EDX analyser incorporating an X-Max silicon drift detector (SDD) and Aztec Energy software. This allowed regions of interest to be scanned and subsequently analysed providing elemental spectra data on selected features.

\section{Matrix deposition within hydrogel constructs}

Matrix deposition was investigated in HAPna hydrogels with or without cells following 48 h, 1, 2, 4 and 6 weeks. Triplicate samples were removed from culture and fixed in paraformaldehyde/PBS ( $4 \% \mathrm{w} / \mathrm{v})$ overnight prior to washing in PBS and embedding to paraffin wax using the TP1020 tissue processor (Leica Microsystems, Milton Keynes UK). Following embedding, $4 \mu \mathrm{m}$ sections 
were cut and mounted to positively charged slides (Leica Microsystems, Milton Keynes, UK). Sections were dewaxed in Sub-X (Leica Microsystems, Milton Keynes, UK) $(3 \times 5 \mathrm{~min})$, rehydrated in IMS (Fisher, Loughborough, UK) $(3 \times 5 \mathrm{~min})$ and washed in distilled water ( $5 \mathrm{~min})$. Sections were then stained in either Alizarin Red (2\% w/v, pH 4.2) (Sigma Aldrich, Poole, UK) for $15 \mathrm{~min}$, Alcian Blue (1\% w/v, pH 2.5) (Sigma Aldrich, Poole, UK) in acetic acid (3\% v/v) (Sigma Aldrich, Poole, UK) for 5 min with neutral red (1\% w/v) (Sigma Aldrich, Poole, UK) used as a counter stain for 2 min or stained with Masson's trichrome (Miller\& Miller Ltd, Hainault, UK) according to the manufacturer's instructions. Sections were dehydrated in IMS $(4 \times 10 \mathrm{~min})$, cleared in Sub-X $(3 \times 5 \mathrm{~min})$ and mounted in Pertex (Leica Microsystems, Milton Keynes, UK). All slides were examined with an Olympus BX51 microscope and images captured by digital camera and Capture Pro OEM v8.0 software (Media Cybernetics, Buckinghamshire, UK). Histological sections were analysed, features noted and images were captured to document their histological appearance. The matrix staining intensity was then evaluated using lineprofile analysis on the Capture Pro OEM v8.0 software (Media Cybernetics, Buckinghamshire, UK). An image was captured for each triplicate sample following $48 \mathrm{~h} 1$, 2, 4 and 6 weeks, 10 random fields were selected per image and line profile analysis undertaken, which provides index values as a measure of intensity for each pixel position in the selected field. The index values per field were averaged to give 10 intensity measurements per triplicate sample and thus 30 measurements per time point.

\section{Immunohistochemistry}

Protein expression of collagen type X, a marker of late stage chondrocyte hypertrophy, the osteoblast specific transcription factor runx 2 and osteogenic matrix markers collagen type I, osteocalcin and osteopontin were selected for immunohistochemistry (IHC) investigation to assess the osteogenic differentiation capacity of hMSCs cultured in L-pNIPAM-co-DMAc hydrogel constructs containing $0.5 \mathrm{mg} / \mathrm{mL}$ HAPna. Additionally, protein expression of aggrecan and collagen type II were also selected for IHC investigation to assess chondrogenesis. All IHC analysis was performed on acellular L-pNIPAM-co-DMAc hydrogel constructs containing $0.5 \mathrm{mg} / \mathrm{mL}$ HAPna for each time point investigated to serve as background controls. IHC analysis was not undertaken on hMSC or acellular hydrogel constructs containing $1.0 \mathrm{mg} / \mathrm{mL}$ HAPna due to evidence of cytotoxicity, reduced matrix deposition and reduced mechanical properties observed in these constructs. Sections were prepared as described for histological analysis; IHC was performed as previously described (Le Maitre et al., 2005). Briefly, $4 \mu \mathrm{m}$ paraffin sections were de-waxed, rehydrated and endogenous peroxidaseblocked using hydrogen peroxide (Sigma, Aldrich Poole UK). After washing in tris-buffered saline (TBS; $20 \mathrm{mM}$ tris, $150 \mathrm{mM}$ sodium chloride, $\mathrm{pH}$ 7.5), sections were subjected to either no antigen retrieval (NAR) or enzymeinduced antigen retrieval (EAR) (30-min incubation in TBS; $20 \mathrm{mM}$ tris, $150 \mathrm{mM}$ sodium chloride, $46.8 \mathrm{mM}$ calcium chloride dihydrate) (Fisher, Loughborough UK)
pH 7.5, containing $0.01 \% \mathrm{w} / \mathrm{v} \alpha$-chymotrypsin (Sigma Aldrich, Poole UK) from bovine pancreas at $37{ }^{\circ} \mathrm{C}$ (Table 2). Following TBS washing, nonspecific binding sites were blocked at room temperature for 90 min with serum $(25 \% \mathrm{w} / \mathrm{v})$ (Abcam, Cambridge, UK) (Table 2) in bovine serum albumin in TBS $(1 \% \mathrm{w} / \mathrm{v})$. Sections were incubated overnight at $4{ }^{\circ} \mathrm{C}$ with the appropriate primary antibody (Table 2). Negative controls, in which mouse or rabbit IgGs (Abcam Cambridge UK) replaced the primary antibody at an equal protein concentration, were used (Table 2). After washing in TBS, sections were incubated in 1:500 biotinylated secondary antibody (Table 2). Disclosure of secondary antibody binding was by the HRP-streptavidin biotin complex (30 min incubation) (Vector Laboratories, Peterborough, UK), TBS washing, followed by application of hydrogen peroxide $(0.08 \% \mathrm{v} / \mathrm{v})$ in 3,3'-diaminobenzidine tetrahydrochloride $(0.65 \mathrm{mg} / \mathrm{mL})$ (Sigma Aldrich, Poole UK) in TBS (20 min incubation). Sections were counterstained with Mayer's haematoxylin (Leica Microsystems, Milton Keynes UK), dehydrated in IMS (Fisher, Loughborough UK) $(4 \times 10 \mathrm{~min})$, cleared in Sub-X (Leica Microsystems, Milton Keynes UK) $(3 \times 5 \mathrm{~min})$ and mounted in Pertex (Leica Microsystems, Milton Keynes UK). All slides were visualised using an Olympus BX51 microscope and images captured by digital camera and Capture Pro OEM v8.0 software (Media Cybernetics, Buckinghamshire, UK). Evaluation of IHC staining was performed by counting immuno positive and immuno negative cells for each section and immunopositive cells expressed as a percentage of total count.

\section{Feasibility testing of injection into bone}

Liquid L-pNIPAM-co-DMAc hydrogel was injected via a 26-gauge needle into a bovine tail vertebra to simulate the potential clinical application. A $3 \mathrm{~mm}$ bore hole was first created in the cortical bone to facilitate needle insertion. A blue dye was incorporated into the liquid L-pNIPAMco-DMAc hydrogel to aid visualisation within the bone following injection. L-pNIPAM-co-DMAc hydrogel was cooled and maintained at $39{ }^{\circ} \mathrm{C}$ in a water bath prior to injection. Approximately $100 \mu \mathrm{L}$ of liquid L-pNIPAM-coDMAc hydrogel was then injected into the centre of the bovine tail vertebra in a temperature controlled glove box set at $37^{\circ} \mathrm{C}$. The vertebra was then cut open and photos captured to investigate the ability of the hydrogel to be injected into bone, fill the voids between the bone trabecula and solidify following injection. Bovine tail vertebrae, without the injection of hydrogel, were also cut open and images captured to serve as controls.

\section{Data processing and statistical analysis}

All tests were performed at least in triplicate. Data were assessed for normality using the Shapiro Wilks test and found to be non-normally distributed, as such data were non-parametric and hence statistical comparisons were performed by Kruskal-Wallis for pairwise comparisons (Conover-Inman) with statistical significance accepted at $p \leq 0.05$. Pairwise comparisons were made as follows: 0 days compared with 1, 2, 3 and $7 \mathrm{~d}$ for Alamar Blue assay (Fig. 1); 0.5 compared with $1.0 \mathrm{mg} / \mathrm{mL}$ HAPna as well 
as hMSC compared with acellular hydrogels for DMA (Fig. 2A,B); $48 \mathrm{~h} \mathrm{hMSC}$ hydrogels compared with all other hMSC scaffolds following 1, 2, 4 and 6 weeks for pore sizes (Fig. 4C), total mass, water mass, dry mass and hydration degree (Fig. 2C-H) and matrix staining intensity measurements (Fig 6A-C); monolayer controls compared with all other time points investigated for IHC (Fig. 9). Data were then presented on graphs; all replicates have been shown with median value indicated to demonstrate clearly the spread of replicates.

\section{Results}

Cytocompatibility assessment of hydroxyapatite hydrogel scaffolds

Alamar Blue assay, as a measure of metabolic cell activity and thus the total number of viable cells, was assessed over $7 \mathrm{~d}$ in culture (Fig. 1). No significant difference in metabolic cell activity was detected over the $7 \mathrm{~d}$ culture period where hMSCs were incorporated into L-pNIAPMco-DMAc hydrogel constructs without HAPna (Fig. 1A) and with $0.5 \mathrm{mg} / \mathrm{mL}$ HAPna (Fig. 1B). A significant decrease in metabolic cell activity was observed from 0 to $2 \mathrm{~d}(p=0.0191), 3$ days $(p=0.0001)$ and $7 \mathrm{~d}(p=0.0001)$ in culture, with increasing HAPna concentration to $1.0 \mathrm{mg} /$ mL HAPna (Fig. 1C).

\section{Mechanical properties}

The mechanical properties of acellular control and hMSC L-pNIPAM-co-DMAc hydrogels, prior to culture (Fig. 2A) and following culture in MSC medium with and without incorporation of MSCs, containing either $0.5 \mathrm{mg} / \mathrm{mL}$ or $1.0 \mathrm{mg} / \mathrm{mL}$ HAPna were characterised using DMA under confined compression after 4 and 6 weeks in culture (Fig. $2 \mathbf{B}, \mathbf{C})$. The elastic modulus (G') values, for all hydrogel formulations, did not increase as a function of increasing frequency indicating that both acellular and hMSC HAPna hydrogels did not exhibit typical viscoelastic behaviour (Fig. 2A,B,C). Since the elastic modulus for all formulations was frequency independent, $1 \mathrm{~Hz}$ was selected to compare potential differences in the mechanical properties between hMSC and acellular HAPna hydrogel scaffolds (Fig. 3A,B). The G' of no cell control L-pNIPAMco-DMAc hydrogels prior to culture with either $0.5 \mathrm{mg} /$ $\mathrm{mL}$ or $1.0 \mathrm{mg} / \mathrm{mL}$ HAPna was $0.99 \mathrm{MPa}$ (range $0.91-1.11$ ) and 1.16 (range 0.71-1.57) respectively (Fig. 2A,B,C), with no significant change upon culture for 6 weeks without cells (Fig. 2A,B,C). Observations revealed a higher $\mathrm{G}^{\prime}$ in hMSC hydrogel constructs with $0.5 \mathrm{mg} / \mathrm{mL}$ HAPna after both 4 and 6 weeks culture with a significantly higher $G^{\prime}$ observed following 6 weeks in comparison with acellular hydrogels with $0.5 \mathrm{mg} / \mathrm{mL}$ HAPna $(p=0.0395)$ and $1.0 \mathrm{mg} /$ mL HAPna $(p=0.0005)$ (Fig. 3B). A significantly higher $G^{\prime}$, following 6 weeks in culture, was also observed in hMSC hydrogel constructs with $0.5 \mathrm{mg} / \mathrm{mL}$ HAPna is comparison to hMSC hydrogels containing $1.0 \mathrm{mg} / \mathrm{mL}$ HAPna ( $p=0.0063$ ) (Fig. 3B). Similarly, an increase in $\mathrm{G}^{\prime}$ in hMSC hydrogels containing $1.0 \mathrm{mg} / \mathrm{mL}$ HAPna following 6 weeks culture (although not significant) was observed in comparison to acellular hydrogels containing

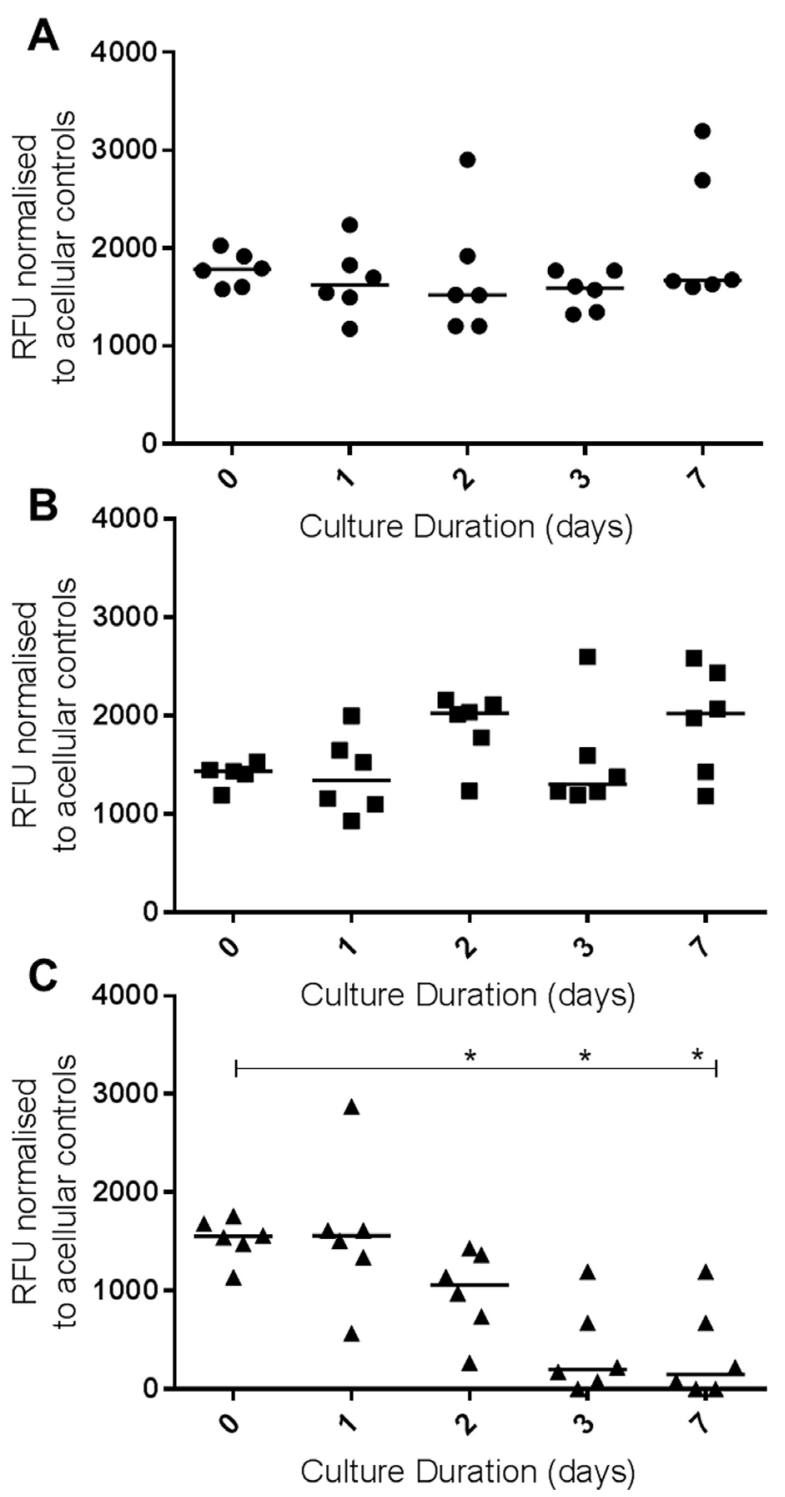

Fig. 1. In vitro cell proliferation using Alamar blue assay of hMSC incorporated into L-pNIPAM-co-DMAc hydrogel (A), incorporated with $0.5 \mathrm{mg} / \mathrm{mL}$ HAPna (B) or $1.0 \mathrm{mg} / \mathrm{mL}$ HAPna (C) following $7 \mathrm{~d}$ in culture. Relative fluorescence units (RFU) normalised to acellular controls. ${ }^{*} p \leq 0.05$.

$1.0 \mathrm{mg} / \mathrm{mL}$ HAPna (Fig. 3A,B). Acellular hydrogels containing $0.5 \mathrm{mg} / \mathrm{mL}$ HAPna also displayed a significantly higher elastic modulus following 6 weeks in culture compared to acellular hydrogels containing $1.0 \mathrm{mg} / \mathrm{mL}$ HAPna $(p=0.0176)$ (Fig. 3B).

\section{Gelation temperature}

The gelation temperature of Liquid L-pNIPAM-co-DMAc hydrogel suspension with $0.5 \mathrm{mg} / \mathrm{mL}$ HAPna, determined using a digital calibrated thermometer, was shown to be $37.1 \pm 0.16^{\circ} \mathrm{C}$ (Table 1$)$.

\section{Structural and compositional requirements for bone regeneration}

Hydration assessment

The addition of hMSCs to hydrogel scaffolds constricted the scaffold size (Fig. 4D). A significant loss of water was 

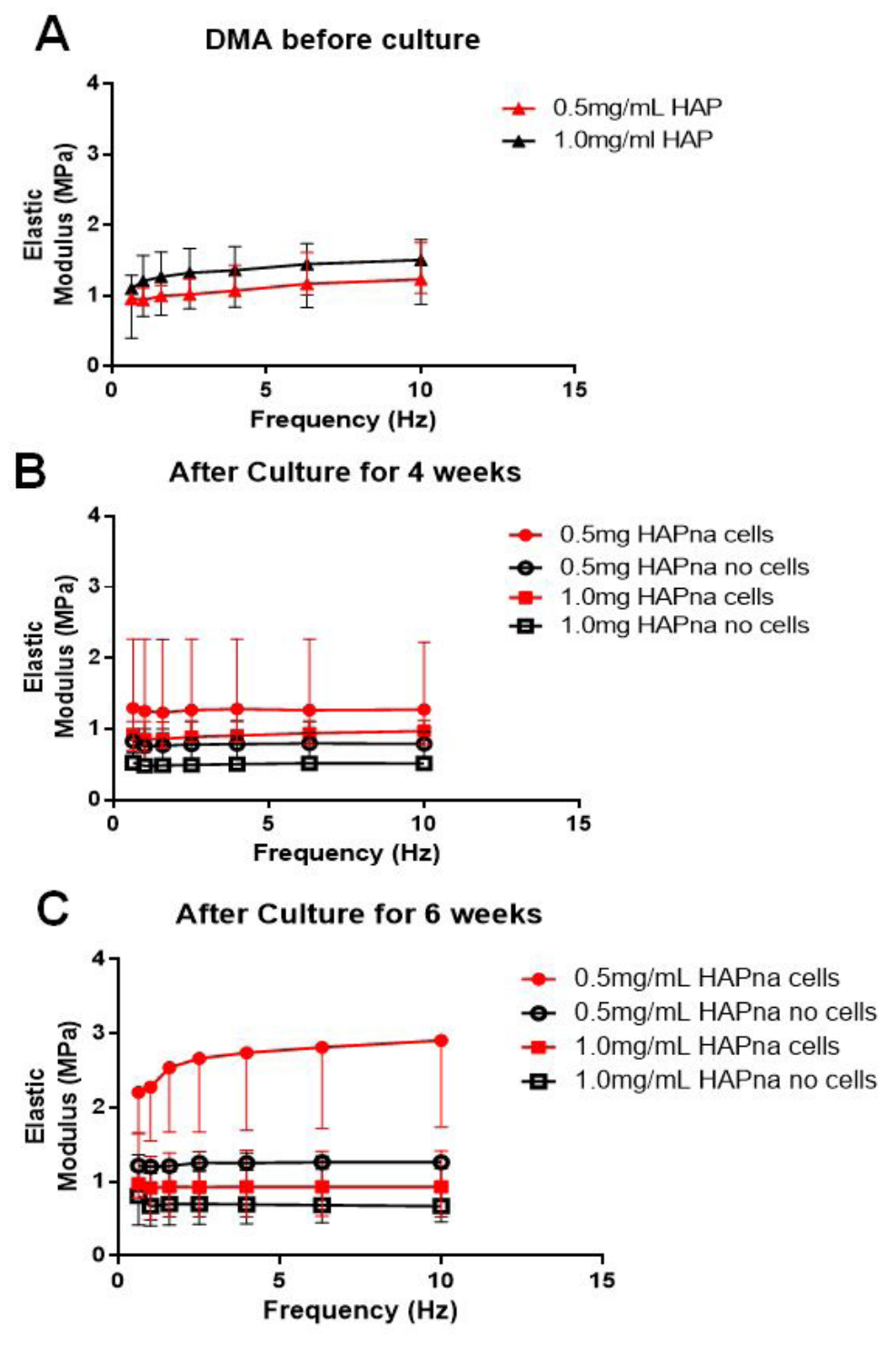

Fig. 2. Dynamic Mechanical Analysis: (A) G'values of acellular L-pNIPAM-co-DMAc hydrogels containing either 0.5 or $1.0 \mathrm{mg} /$ mL HAPna prior to culture (storage time $2 \mathrm{~h}$ ), under confined compression from 0.63 to $10 \mathrm{~Hz}$. $(\mathbf{B}, \mathbf{C})$ Acellular control and hMSC L-pNIPAM-co-DMAc hydrogels containing 0.5 or $1.0 \mathrm{mg} / \mathrm{mL}$ HAPna, afer $4(\mathbf{B})$ and $6(\mathbf{C})$ weeks in culture under confined compression from 0.63 to $10 \mathrm{~Hz}$. containing $0.5 \mathrm{mg} / \mathrm{mL}$ HAPna from 2 to 6 weeks (Fig. 4A) with a significant decrease in pore size from $48 \mathrm{~h}$ to 2 weeks in culture $(p<0.0001)$, which subsequently became too small in diameter to obtain accurate measurements after 2 weeks in culture (Fig. 4C). An increase in the structural density of hMSC hydrogels containing $1.0 \mathrm{mg} / \mathrm{mL}$ HAPna was also observed however the structural morphology of the entire construct was not uniform, with areas of high porosity visible following 6 weeks in culture (Fig. 4B). Pore sizes of hMSC scaffolds with $1.0 \mathrm{mg} / \mathrm{mL}$ HAPna were measured throughout the 6 week culture period with a significant decrease in pore size shown from $48 \mathrm{~h}$ to 6 weeks in culture $(p<0.0001)$ (Fig. 4C).

\section{Histological and elemental assessment}

The composition of the matrix was assessed histologically and found to consist of collagen, identified by Masson's trichrome (Fig. 5), with a significant increase in the matrix staining intensity following culture for 1 week $(p=<0.001), 4$ weeks $(p=0.0092)$ and 6 weeks $(p=<0.001)$ in comparison to $48 \mathrm{~h}$ in culture (Fig. 6A), as well as calcium deposition confirmed by alizarin red staining (Fig. 5), with a significant increase in the matrix staining intensity following culture for 4 weeks $(p=0.01)$ 
A

4wk $1 \mathrm{~Hz}$

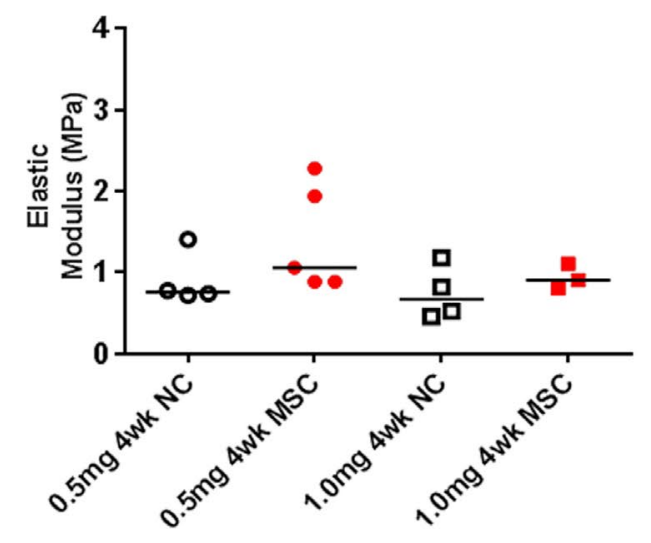

C
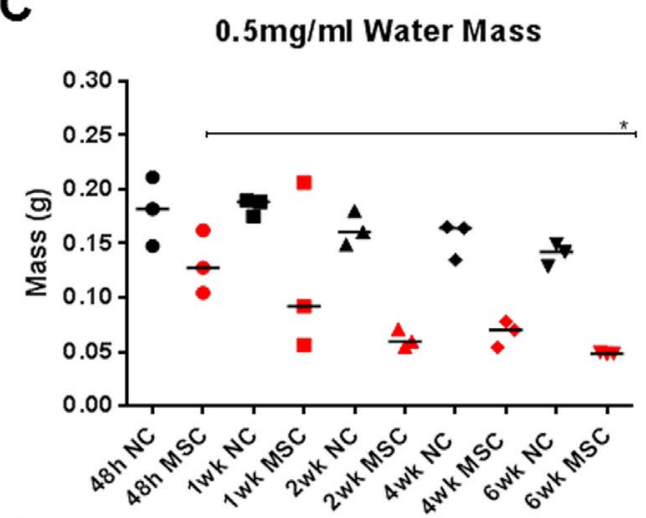

E

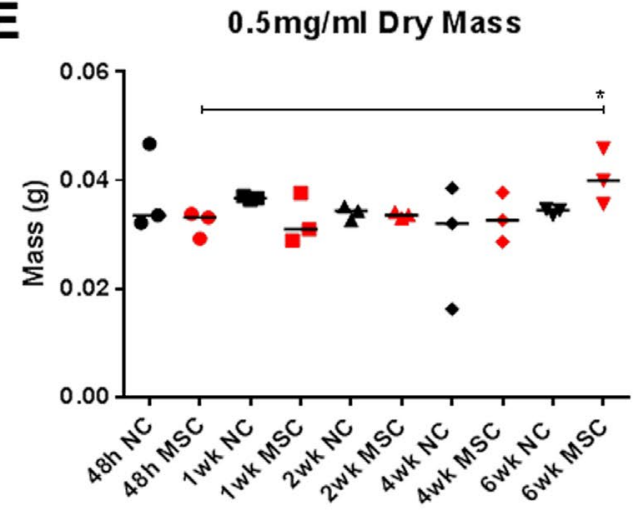

G

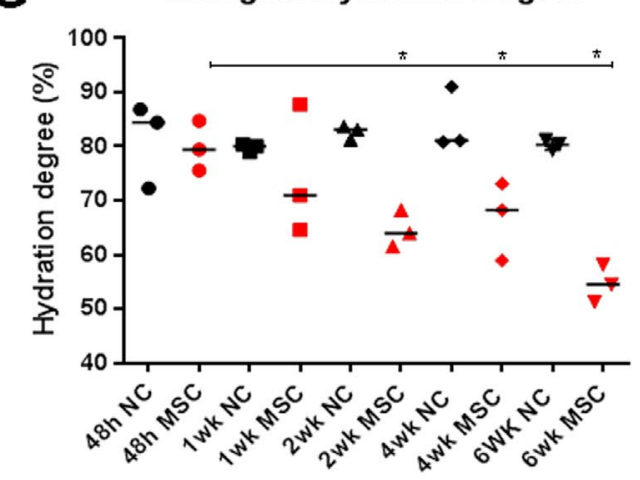

B

6 wk $1 \mathrm{~Hz}$

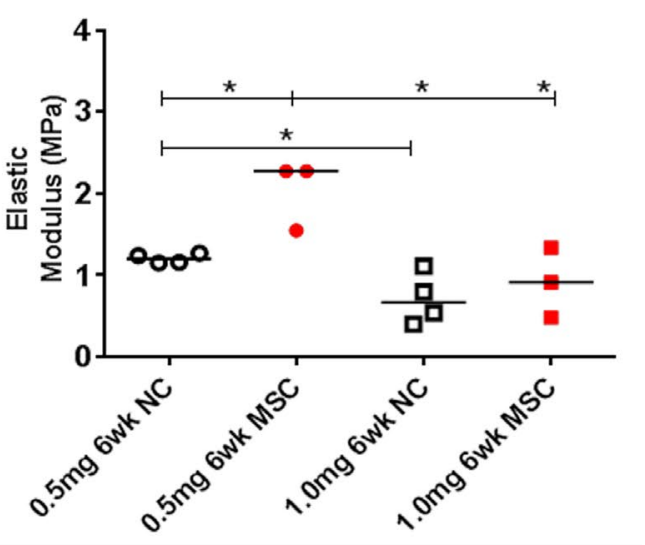

D

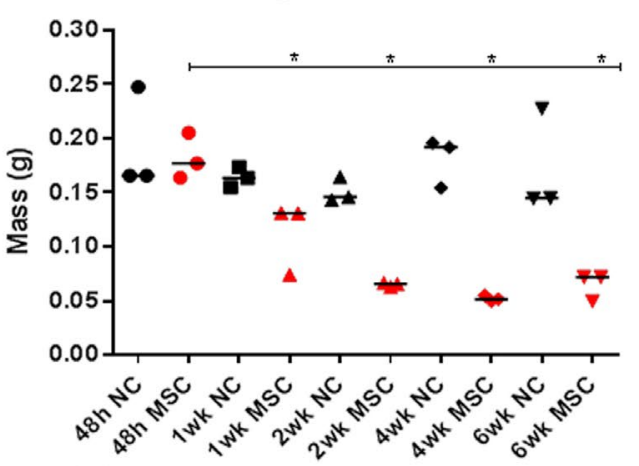

F $\quad 1.0 \mathrm{mg} / \mathrm{ml}$ Dry Mass

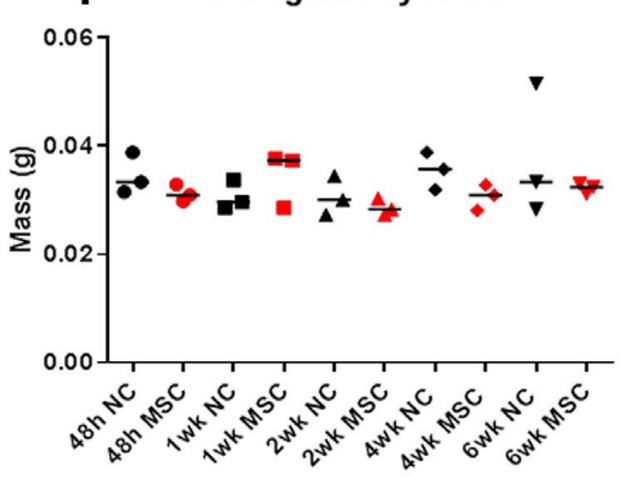

H $1.0 \mathrm{mg} / \mathrm{ml}$ Hydration Degree

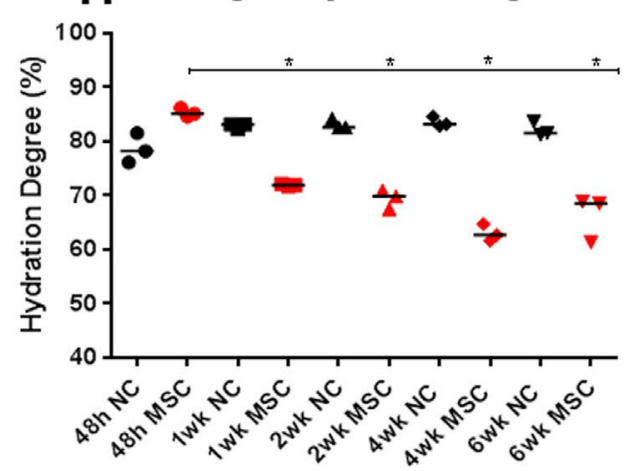

Fig. 3. Structural and Mechanical Characterisation of L-pNIPAM-co-DMAc hydrogels with either $0.5 \mathrm{or} 1.0 \mathrm{mg} / \mathrm{mL}$ HAPna, with hMSC (red) or acellular (NC) controls (black). G' values of hMSC and acellular (NC) hydrogels containing either 0.5 or $1.0 \mathrm{mg} / \mathrm{mL}$ HAPna after 4 (A) and 6 (B) weeks in culture, under confined compression at $1 \mathrm{~Hz}$. Water mass $(\mathbf{C}, \mathbf{D})$, dry mass $(\mathbf{E}, \mathbf{F})$ and calculated hydration degree $(\mathbf{G}, \mathbf{H})$ of hMSC (MSC) and acellular control (NC) hydrogels containing either $0.5(\mathbf{C}, \mathbf{E}, \mathbf{G})$ or $1.0 \mathrm{mg} / \mathrm{mL}(\mathbf{D}, \mathbf{F}, \mathbf{H})$ HAPna throughout 6 weeks in culture. Statistical significance compared to $48 \mathrm{~h}$ hMSC indicated. All replicates shown with median values indicated. ${ }^{*} p \leq 0.05$. 
A
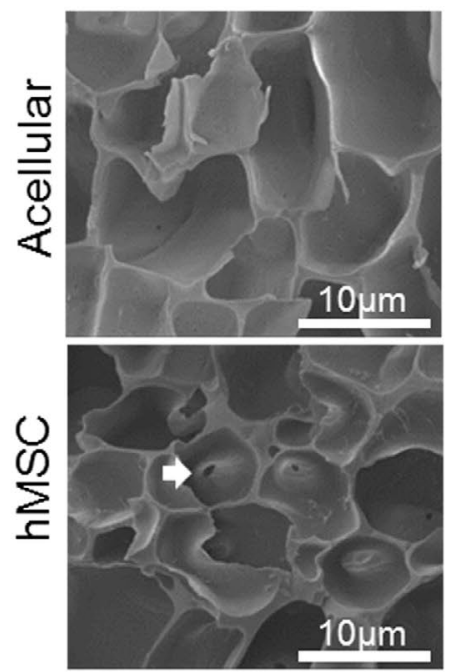

B
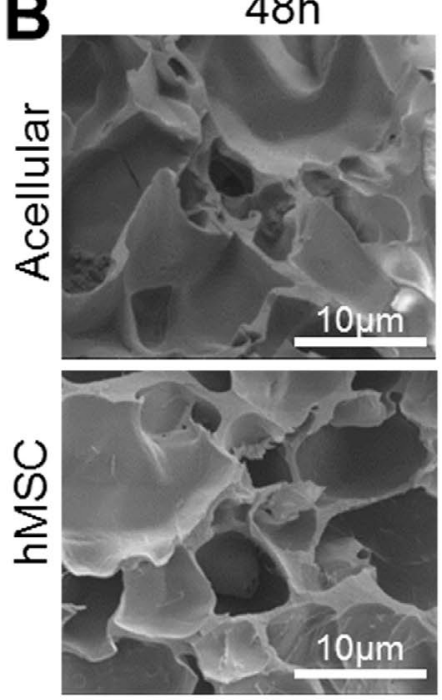

2wk
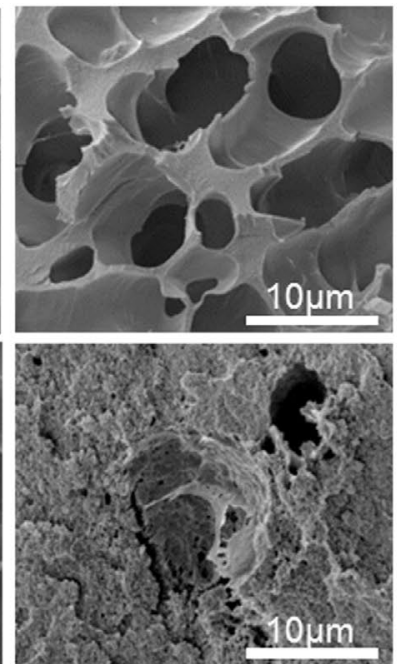

2wk
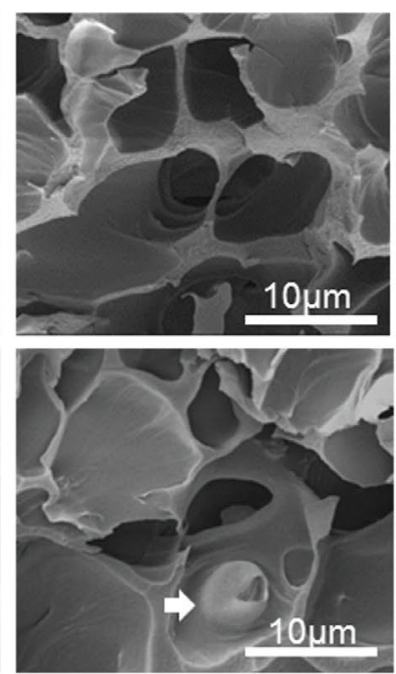

$4 \mathrm{wk}$
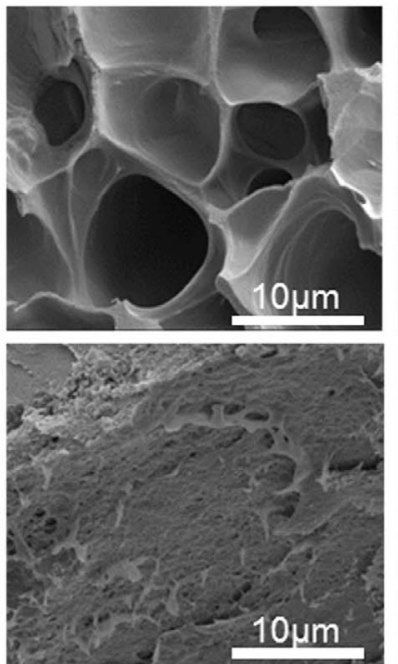

$4 \mathrm{wk}$
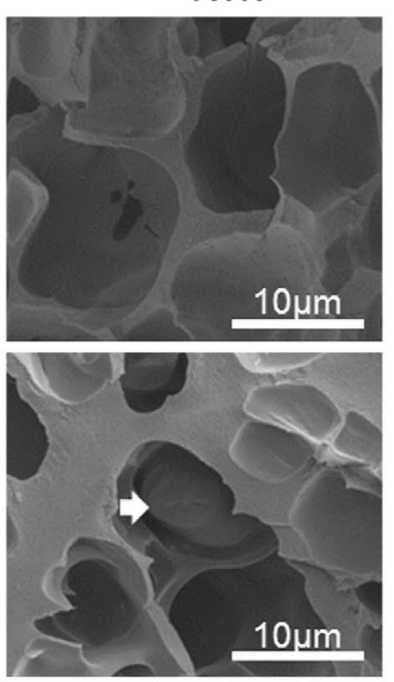

$6 w k$
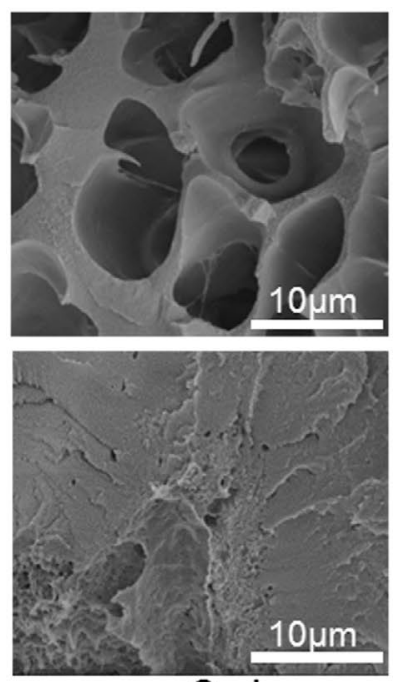

6wk
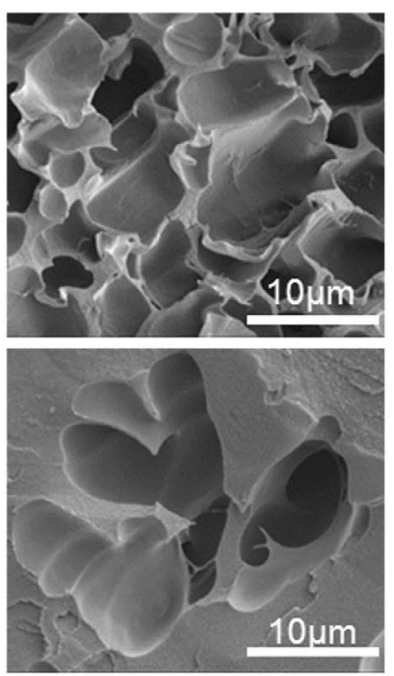
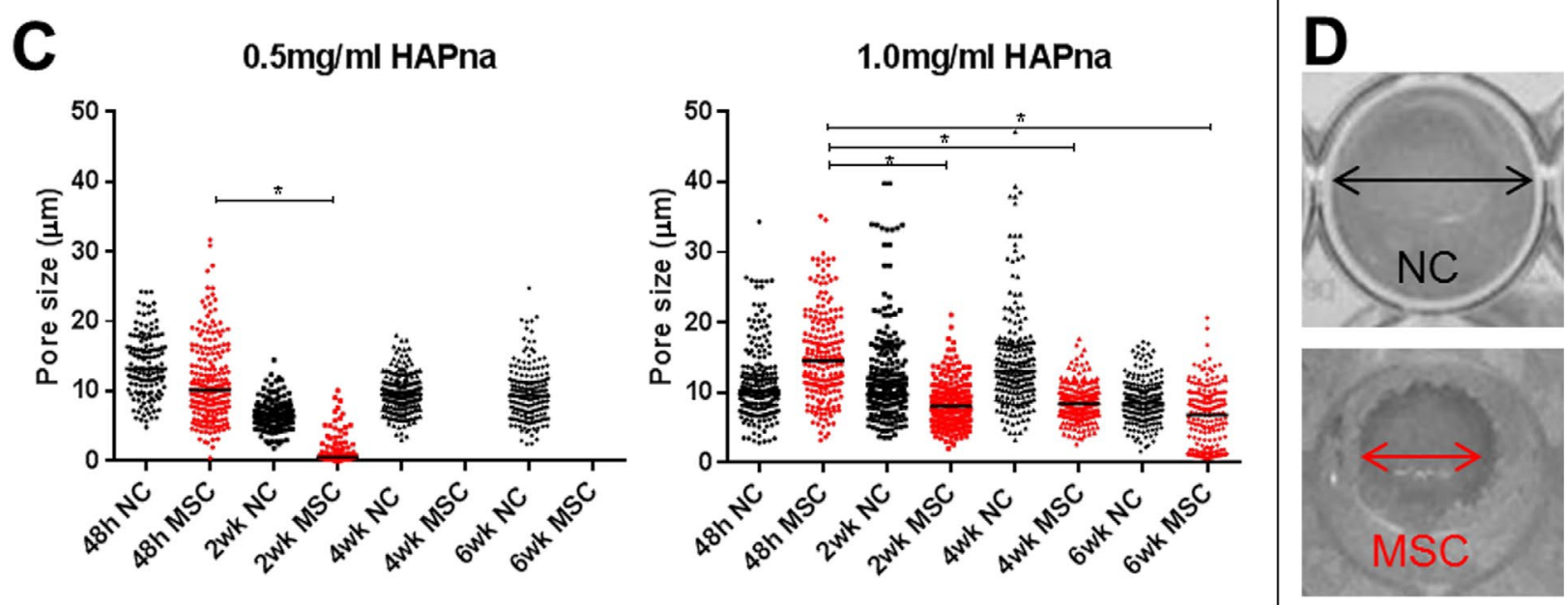

Fig. 4. Scanning electron microscopy (SEM) of hMSC and acellular hydrogels with $0.5 \mathrm{mg} / \mathrm{mL}$ HAPna (A) or $1.0 \mathrm{mg} / \mathrm{mL}$ HAPna (B) from $48 \mathrm{~h}$ to 6 weeks in culture, scale bar $10 \mu \mathrm{m}$. (C) pore sizes ( $\mu \mathrm{m})$ for hMSC and acellular (NC) hydrogels. (D) Images of hydrogels with $0.5 \mathrm{mg} / \mathrm{mL}$ HAPna in culture demonstrating constriction in hydrogel size where hMSCs had been incorporated, images captured following 1 week in culture. Statistical significance compared to $48 \mathrm{~h}$ hMSC indicated. All replicates shown with median values indicated. ${ }^{*} p \leq 0.05$. 


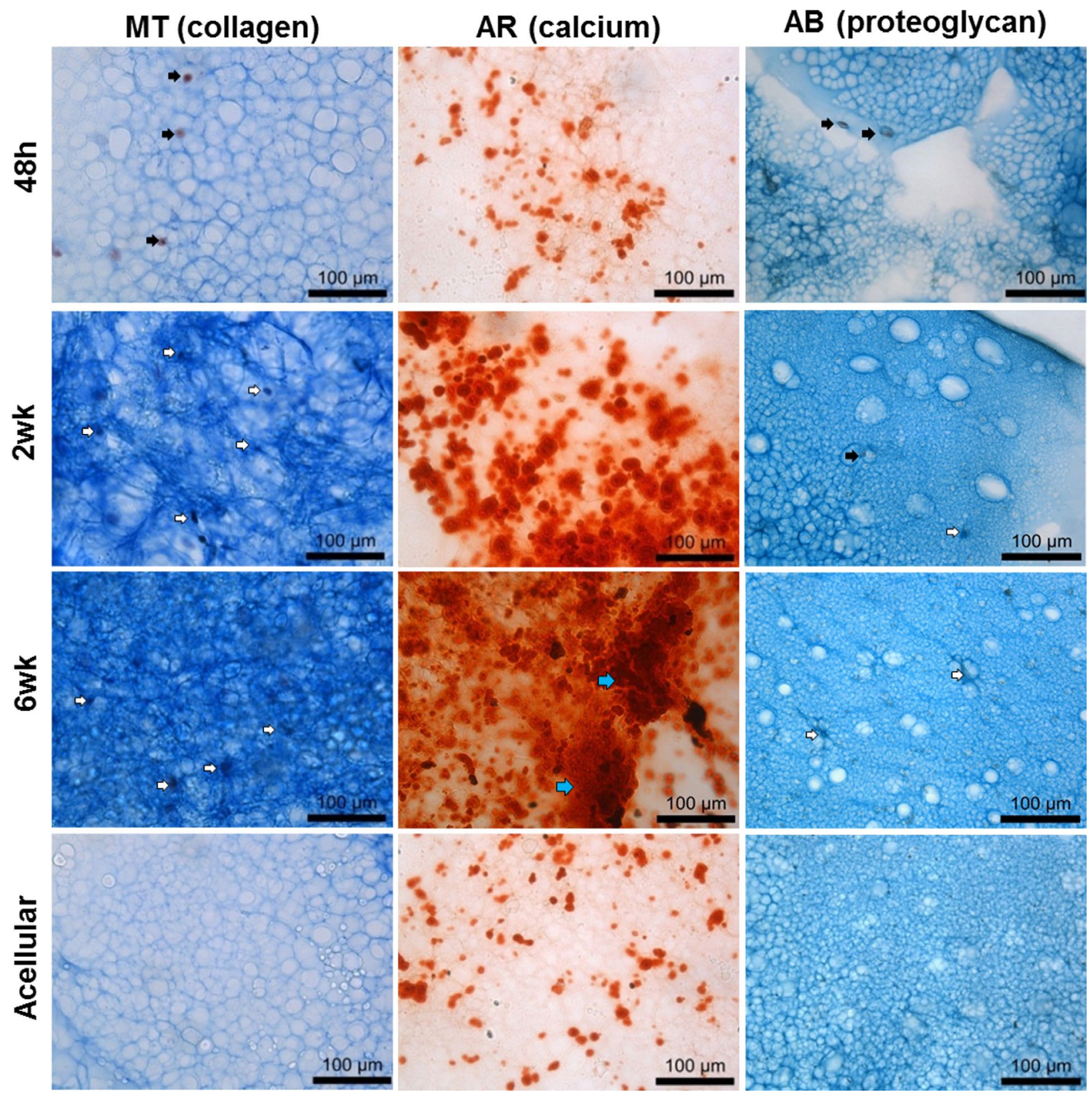

Fig. 5. Analysis of matrix deposition in L-pNIPAM-co-DMAc hydrogel constructs containing $0.5 \mathrm{mg} / \mathrm{mL} \mathrm{HAPna}$ using histological stains: Masson's trichrome (MT) for collagen, alizarin red (AR) for calcium deposition and alcian blue (AB) for proteoglycans. Acellular control hydrogels shown following 6 wks in culture. Black arrows indicate negative cells, white arrows indicate positive matrix producing cells and blue arrows indicate formation of possible osteoid nodules. Scale bar $100 \mu \mathrm{m}$.

and 6 weeks $(p<0.0001)$, compared to $48 \mathrm{~h}$ in culture (Fig. 6B). Mineralisation was further supported by the identification of a calcium and phosphate peak observed using EDX spectra (Fig. 7). Histologically cells were also shown to produce proteoglycans as observed by Alcian Blue staining (Fig. 5), with a significant increase in the matrix staining intensity of hMSC hydrogels after 1 week $(p=0.0485)$ and 4 weeks $(p<0.0001)$ compared to those after $48 \mathrm{~h}$ (Fig. 6C); however, a significant increase in the matrix staining intensity, with alcian blue staining, was also observed in acellular controls following culture for 1 week $(p<0.0001)$ and 6 weeks $(p=0.0023)$ compared to those after $48 \mathrm{~h}$ in culture (Fig. $6 \mathrm{C}$ ).

\section{Induction of osteogenic differentiation}

In the current study, the ability of $0.5 \mathrm{mg} / \mathrm{mL}$ HAPna loaded L-pNIPAM-co-DMAc hydrogels to induce osteogenic differentiation of bone marrow derived hMSCs was assessed by immunohistochemical analysis of hMSCs harvested directly from monolayer culture and after $48 \mathrm{~h}, 1,2,4$ and 6 weeks in hMSC hydrogels containing $0.5 \mathrm{mg} / \mathrm{mL}$ HAPna for collagen type X (Fig. 8), a marker of chondrocyte hypertrophy associated with endochondral ossification (Mwale et al., 2006), the osteoblast specific transcription factor runx 2 and bone matrix markers collagen type I, osteopontin and osteocalcin (Fig. 8). IHC for specific antibodies for the chondrogenic markers: collagen type II and aggrecan were also performed to 
confirm specific matrix synthesis (Fig. 8). Collagen type $\mathrm{X}$ was ubiquitously expressed (100\%) by hMSCs prior to incorporation into $0.5 \mathrm{mg} / \mathrm{mL}$ HAPna hydrogels (Fig. 9), this was followed by a significant decrease in the number of immunopositive cells after culture for $48 \mathrm{~h}(p=0.0016)$, $1(p=0.0102), 2(p=0.0333)$ and $6(p=0.0056)$ weeks in hydrogels containing $0.5 \mathrm{mg} / \mathrm{mL}$ HAPna, in comparison to monolayer controls (Fig.9).

Runx2 immunopositivity was significantly increased after culture for $48 \mathrm{~h}(p=0.0258), 1$ week $(p=0.0005)$ and 2 weeks ( $p=0.0221$ ), in comparison to monolayer controls, after incorporation into hydrogels loaded with $0.5 \mathrm{mg} / \mathrm{mL}$ HAPna; this was followed by a significant decrease in the number of runx 2 immunopositive cells from 2 to 4 weeks $(p=0.0018)$ in culture (Fig. 9).

Collagen type I was found to be highly expressed by hMSCs harvested directly from monolayer culture (98\%) with a significant decrease in the number of immunopositive cells observed after culture for $48 \mathrm{~h}(p=0.0073)$ and 1 week $(p=0.0253)$, following incorporation into hydrogel constructs containing $0.5 \mathrm{mg} / \mathrm{mL}$ HAPna, in comparison to monolayer controls (Fig. 9). A significant increase in collagen type I cell immunopositivity was observed following 4 weeks $(p=0.0013)$ and 6 weeks $(p=0.0003)$ in culture, in comparison to the reduced expression observed after 48 h (Fig. 9). Expression of collagen type I was subsequently maintained at high levels with all three replicates displaying $100 \%$ immunopositivity after 6 weeks in culture (Fig. 9).

Osteopontin and osteocalcin, two late phase markers of mature osteogenesis, were shown to be expressed by a significantly increased number of hMSCs $(p<0.0001)$ from $48 \mathrm{~h}$ to 6 weeks in culture, after incorporation into $0.5 \mathrm{mg} / \mathrm{mL}$ HAPna hydrogel scaffolds in comparison to monolayer controls (Fig. 9).

The percentage cell immunopositivity for chondrogenic markers: aggrecan and collagen type II, remained unchanged (aggrecan) or was significantly decreased (collagen type II) following 4 ( $p=0.0213$ ) and 6 weeks $(p=0.042)$ in culture, after incorporation into $0.5 \mathrm{mg} / \mathrm{mL}$ HAPna hydrogel constructs in comparison to monolayer controls (Fig. 9).

\section{Feasibility of injection into bone}

Liquid L-pNIPAM-co-DMAc hydrogel containing $0.5 \mathrm{mg} / \mathrm{mL}$ HAPna was maintained at $39^{\circ} \mathrm{C}$ and injected through a 26 -gauge needle at $37^{\circ} \mathrm{C}$ demonstrating rapid gelation at $37^{\circ} \mathrm{C}$ (Fig. 10A \& Supplementary Video 1). It is important to note that the liquid L-pNIPAMco-DMAc maintained at $39{ }^{\circ} \mathrm{C}$ remained in the liquid state and would do so indefinitely at this temperature. The proposed clinical application would be performed by combining liquid L-pNIPAM-co-DMAc hydrogel containing HAPna and previously extracted autologous MSCs prior to injection into the bone site required, where cooling to body temperature $\left(37^{\circ} \mathrm{C}\right)$ will result in gelation of the hydrogel system (Fig. 10B). To test the feasibility of application of the hydrogel into bone, liquid L-pNIPAMco-DMAc hydrogel containing $0.5 \mathrm{mg} / \mathrm{mL}$ HAPna with an incorporated blue dye for visualisation, was cooled to
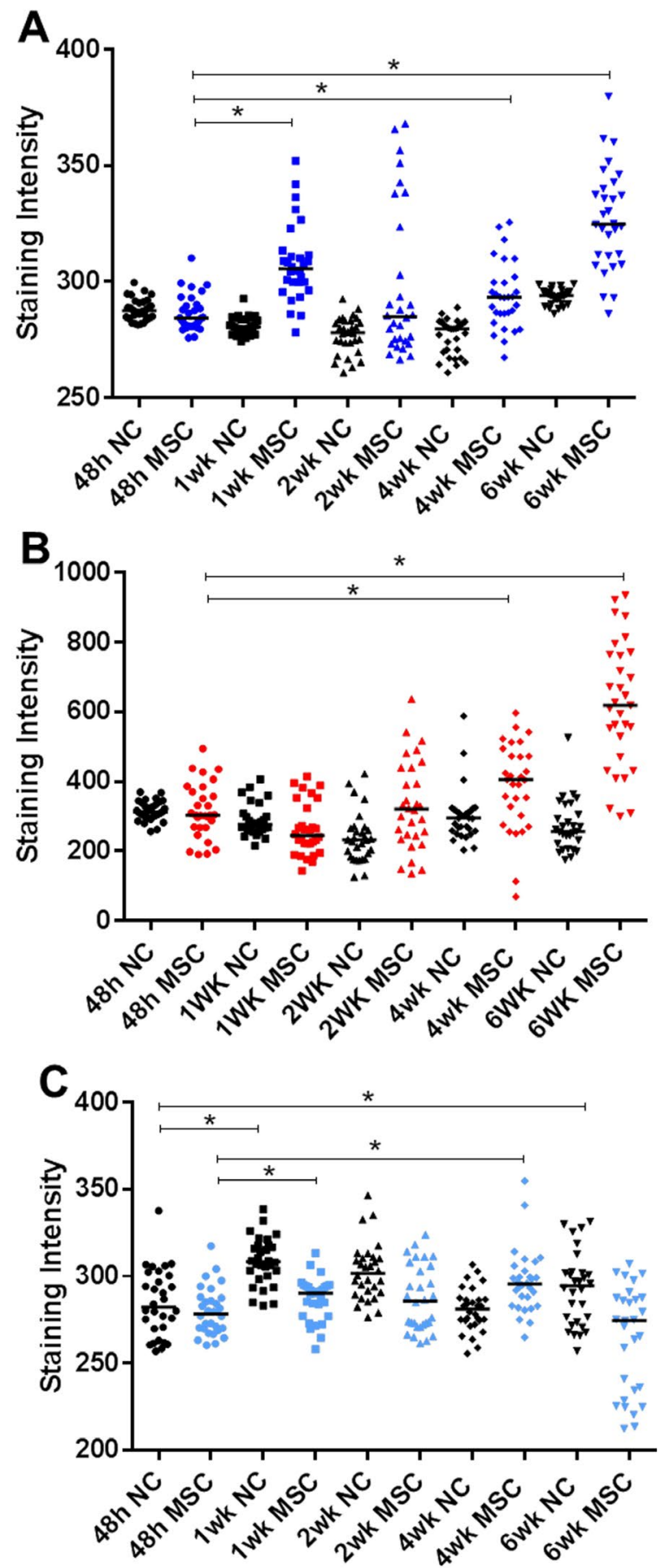

Fig. 6: Line profile analysis providing index values per pixel to calculate matrix staining intensity in hMSC (MSC) and acellular (NC) control L-pNIPAMco-DMAc hydrogel constructs containing $0.5 \mathrm{mg} / \mathrm{mL}$ HAPna using histological stains: Masson's trichrome (A), alizarin red (B) and alcian blue (C). Statistical significance compared to $48 \mathrm{~h} \mathrm{hMSC}$ and $\mathrm{NC}$ indicated. All replicates shown with median values indicated. ${ }^{*} p \leq 0.05$.

$39^{\circ} \mathrm{C}$ and injected into bovine tail vertebrae at $37^{\circ} \mathrm{C}$ (Fig. $10 \mathrm{C})$. Following injection, the vertebrae was cut open and inspected, the hydrogel was found to have filled the voids between the bone trabecula and solidified post-injection (Fig. 10C). 


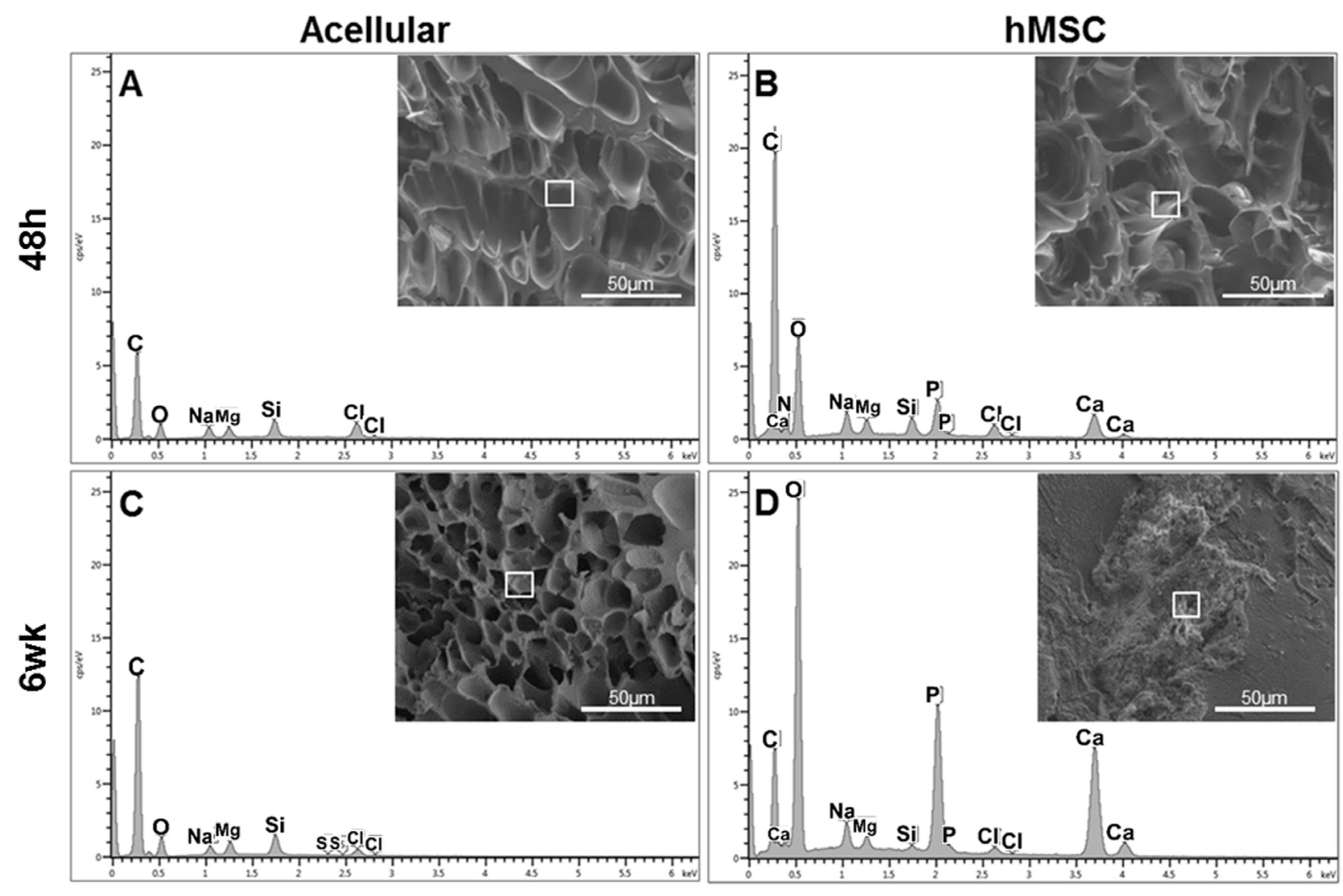

Fig. 7. EDX spectra of L-pNIPAM-co-DMAc hydrogels with $0.5 \mathrm{mg} / \mathrm{mL}$ HAPna. Acellular control hydrogel after $48 \mathrm{~h}$ in culture (A), hMSC hydrogel after $48 \mathrm{~h}$ in culture (B), acellular control hydrogel after 6 weeks in culture (C), hMSC hydrogel after 6 weeks in culture (D). SEM images illustrated inset, white box indicates where EDX spectra were collected. Scale bar $50 \mu \mathrm{m}$.

\section{Discussion}

\section{Cytocompatibility assessment of hydroxyapatite hydrogel scaffolds}

The cytocompatibility of biomaterial scaffolds is a fundamental prerequisite for use therapeutically. The survival of cells incorporated into liquid hydrogel prior to gelation offers key advantages, over previously developed pNIPAM hydrogels which required solidification and purification prior to the addition of cells, both of which eliminate any potential as an injectable delivery system (Haraguchi et al., 2006). Cell viability was maintained in $0.5 \mathrm{mg} / \mathrm{mL}$ HAPna containing hydrogels, but no increase in cell number was seen indicating that cells were not proliferating in the hydrogel constructs; however, studies have shown that commitment to the osteogenic lineage, depicted by the up-regulation of the osteoblast specific transcription factor runx2, results in down regulation of genes which are required for proliferation (Stein et al., 2004). The structural limitations of a three-dimensional microenvironment and the increasing stiffness which can result from the addition of HAPna may also slow down cellular proliferation (Lei et al., 2011, Sun et al., 1997). Interestingly, cytotoxic effects were observed with increasing HAPna concentration to $1.0 \mathrm{mg} / \mathrm{mL}$ HAPna. HAP cytotoxicity has been reported previously (Qing et al., 2012; Sun et al., 1997), in particular Sun et al., (1997) demonstrated that osteoblast cellular proliferation was significantly reduced when cultured in media containing HAP powder at a concentration of $1.0 \mathrm{mg} / \mathrm{mL}$, as was used in this study, thus highlighting the importance of testing nanoparticle concentrations over a narrow range of the desired concentration to assess potential toxicity (Sun et al., 1997).

\section{Mechanical properties}

The unique nanostructure of bone ensures exceptional mechanical properties with an elastic modulus in the region of 14-20 GPa for cortical bone and approximately $10 \mathrm{GPa}$ for cancellous bone (Choi et al., 1990; Reilly et al., 1974; Rho et al., 1993; Rho et al., 1997; Rho et al., 1998). Traditionally, hydrogels have been considered for the regeneration of soft tissues, due to their inherently weak mechanical properties, studies have also shown that addition of cells further exacerbates this problem (Kumar et al., 2014). However, observations in this study, revealed an increased elastic modulus from 1.21 MPa in acellular hydrogel scaffolds with $0.5 \mathrm{mg} / \mathrm{mL}$ HAPna to $2.03 \mathrm{MPa}$ in hMSC hydrogels with $0.5 \mathrm{mg} / \mathrm{mL}$ HAPna following 6 weeks in culture, possibly due to a combination of matrix deposition and reduced hydration degree in cellular hydrogel scaffolds.

The decrease in elastic moduli observed with increasing HAPna concentration has been previously reported by 


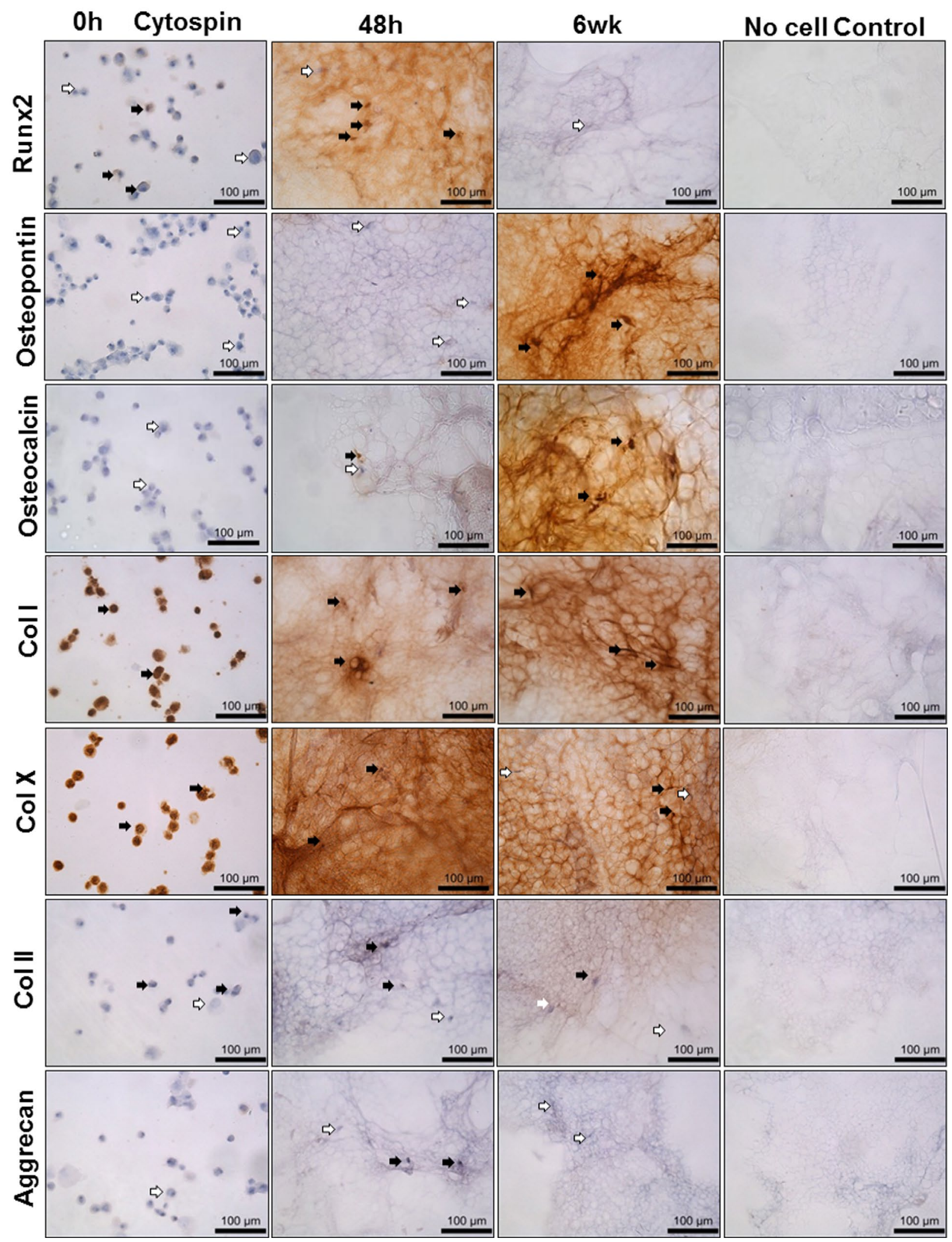

Fig. 8. Immunohistochemical detection of osteogenic markers runx2, osteopontin, osteocalcin, collagen type I, collagen type $\mathrm{X}$ and negative markers collagen type II and aggrecan, prior to hydrogel incorporation $(0 \mathrm{~h})$ (monolayer control) and after $48 \mathrm{~h}$ and 6 weeks following incorporation into hydrogel. Acellular control hydrogels shown to match the time point at which \% immunopositivity was highest: runx2, col type II (48 h), col type I, osteopontin, osteocalcin (6 weeks), and aggrecan, col type X (4 weeks). Black arrows indicate positively stained cells and white arrows indicate negatively stained cells. Scale bar $100 \mu \mathrm{m}$. 
Runx2

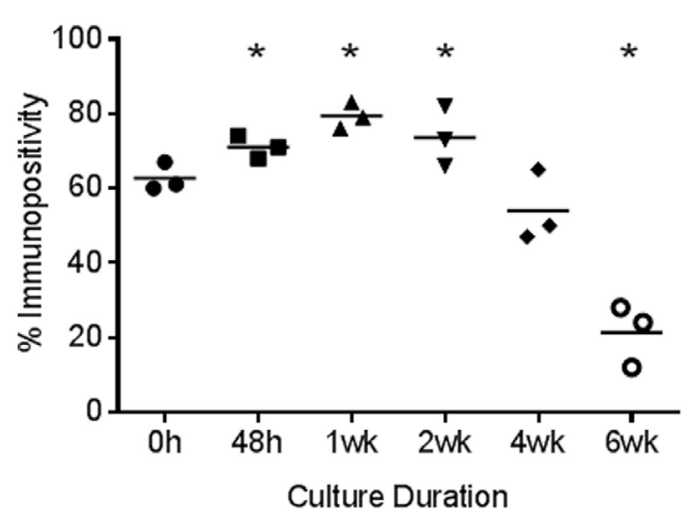

Ostecalcin

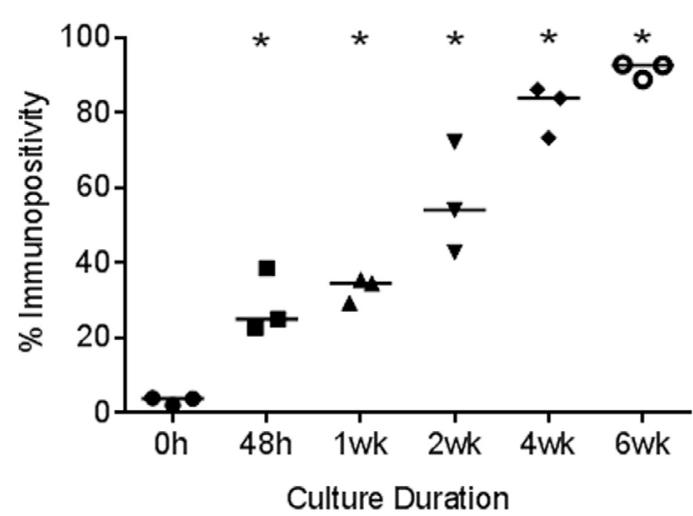

Col X

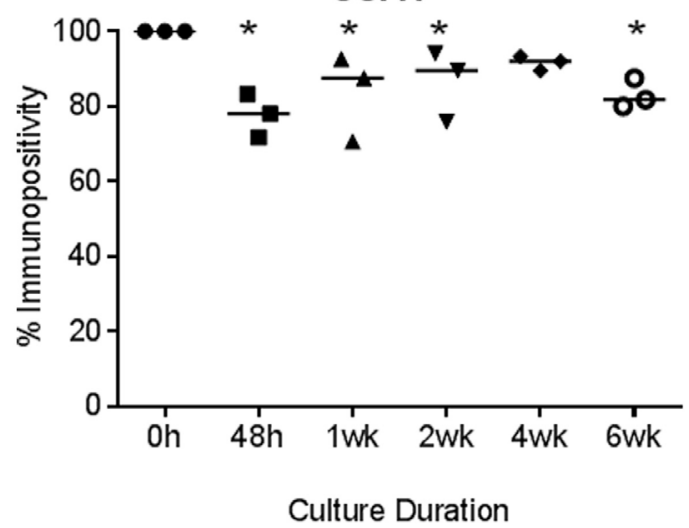

Col I

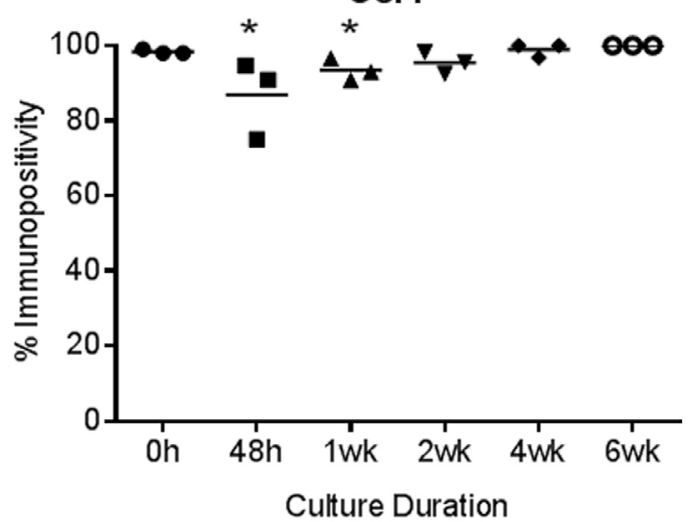

Osteopontin

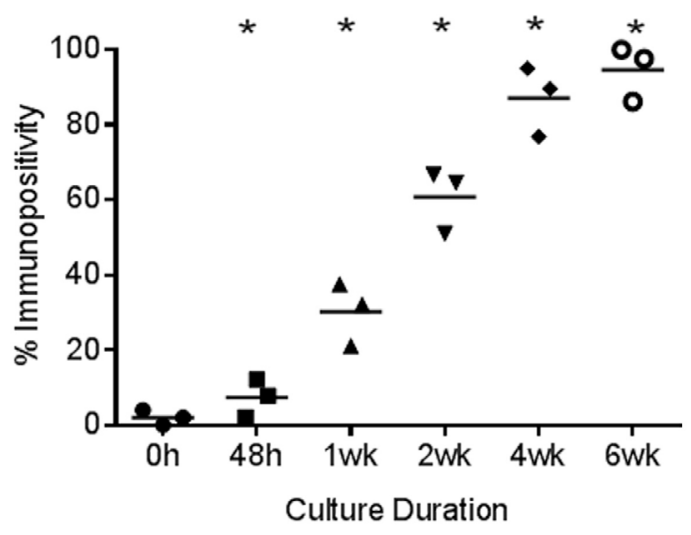

Col II

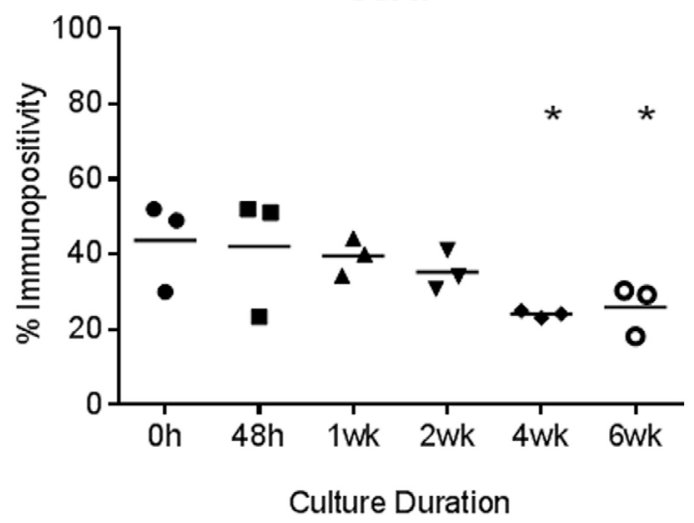

Aggrecan

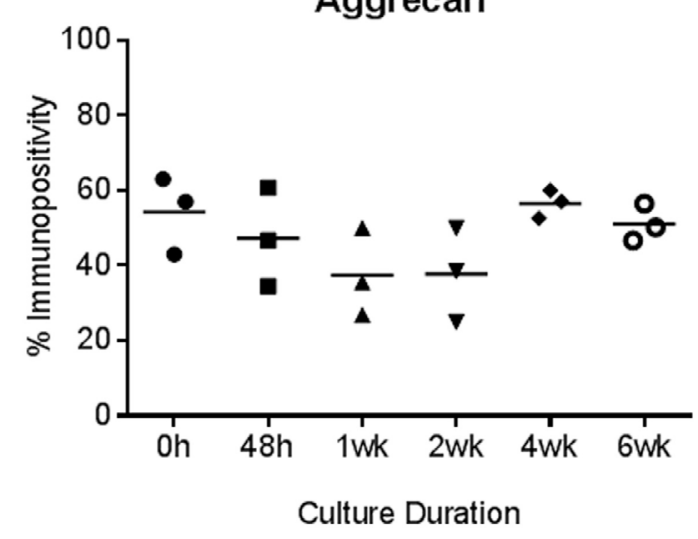

Fig. 9. Immunohistochemical detection of osteogenic markers runx2, osteopontin, osteocalcin, collagen type I, collagen type $\mathrm{X}$ and negative markers collagen type II and aggrecan prior to hydrogel incorporation ( $0 \mathrm{~h})$ (monolayer controls) and after 48 h, 1, 2, 4 and 6 weeks culture following incorporation into hydrogel. Percentage immunopositivity was calculated and statistical analysis performed to investigate change from control $\left({ }^{*} p \leq 0.05\right)$. 


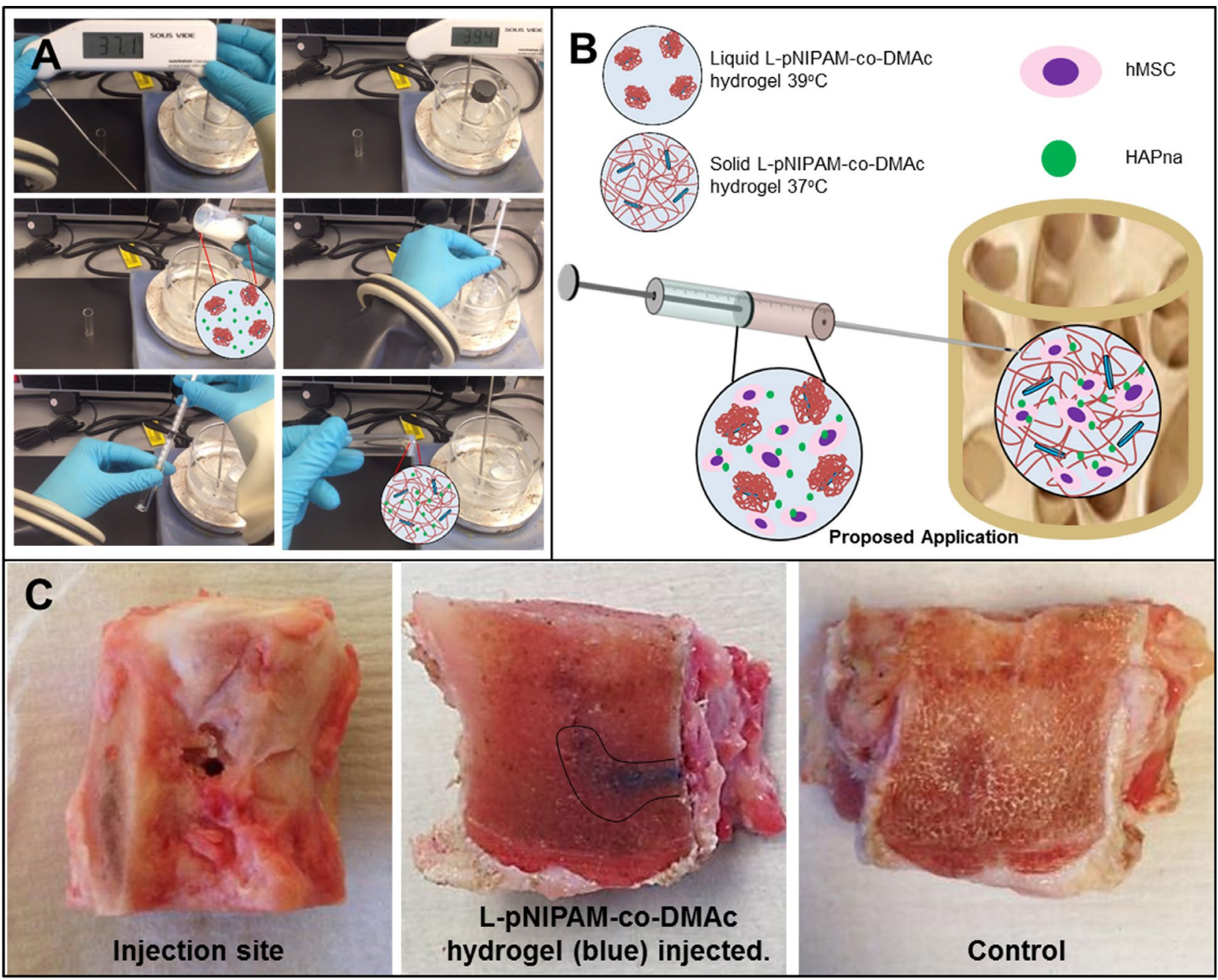

Fig. 10. Injection into bone simulation: (A) still images captured from video which demonstrates liquid L-pNIPAMco-DMAc hydrogel with $0.5 \mathrm{mg} / \mathrm{mL}$ HAPna, cooled to $39^{\circ} \mathrm{C}$ in a water bath and injected (26 gauge) into a glass vial, followed by rapid solidification inside a temperature controlled glove box set to $37{ }^{\circ} \mathrm{C}$. (B) Schematic illustrating liquid L-pNIPAM-co-DMAc hydrogel cooled to $39{ }^{\circ} \mathrm{C}$ (above the gelation temperature) where the hydrogel exists as a low viscosity colloidal suspension where HAPna and hMSC can be incorporated. Following injection into the bone tissue and further cooling to $37^{\circ} \mathrm{C}$ the polymer chains uncoil and entangle forming a 3-dimensional hydrogel network, encapsulating both the HAPna and the hMSC. (C) Injection of L-pNIPAM-co-DMAc hydrogel, with a blue dye incorporated for visualisation, into bovine tail vertebra.

Pan et al., 2008, who observed a decrease in G' with increasing HAPna content from $6 \%$ to $9 \%$ in poly (vinyl alcohol) gel biocomposites (Pan et al., 2008). It is well known that the addition of HAP can greatly affect the rheological properties of polymeric composites (Pan et al., 2008), particularly at low HAP concentrations where the addition of HAPna has been shown to increase the stiffness of composites due to the rigidity of HAPna (Pan et al., 2008). However, the high surface energy of HAPna can cause them to agglomerate at high concentrations, which can lead to deterioration of mechanical properties (Liu et al., 1997). It could also be hypothesised that increasing the concentration of HAPna from 0.5 to $1.0 \mathrm{mg} / \mathrm{mL}$ HAPna results in an effective lower cross linking density, due to the HAPna competing with the pNIPAM amide groups on the gel backbone for interaction with exchange cations and electron rich areas on the Laponite ${ }^{\circledR}$ surface. This phenomenon could explain the reduced mechanical properties observed here where $1.0 \mathrm{mg} / \mathrm{mL}$ HAPna was incorporated into hydrogel scaffolds, compared to those of the $0.5 \mathrm{mg} / \mathrm{mL}$ HAPna containing systems. Studies have shown that cells are able respond to the stiffness of their substrate and hence the mechanical properties of the hydrogel scaffold can influence cell function and differentiation (Discher et al., 2005, Wang et al., 2012). Thus, the stiffer hydrogel matrix provided by the addition of $0.5 \mathrm{mg} / \mathrm{mL}$ HAPna could account for the improved osteoconductivity observed in these constructs compared to hMSC hydrogels containing $1.0 \mathrm{mg} / \mathrm{mL}$ HAPna. The mechanical properties of HAPna loaded hydrogels displayed here still fall short of those of native bone, which have been reported to display elastic moduli of 14-20 GPa (cortical bone) (Reilly et al., 1974; Rho et al., 1993; Rho et al., 1997). However, it is hypothesised that the initial mechanical properties of hydrogel scaffolds would not need to match that of native bone, particularly when used 
to deliver hMSC for clinical cases such as osteoporosis and lining of prosthetic implants; in such cases, the native bone surrounding the implantation site would provide the initial mechanical support whilst the hydrogel becomes mineralised by the regenerative capacity of the cells, thus resulting in a biologically functional and integrated tissue/ biomaterial. Furthermore, the use of a non-degradable injectable scaffold would be advantageous over current therapeutic alternatives in such clinical cases, enabling the facile application to micro fissures within the bone and avoiding loss of mechanical properties seen during scaffold degradation in biodegradable scaffolds (Kim et al., 2007, Lutolf and Hubbell, 2005).

\section{Structural and compositional requirements for bone regeneration}

Bone ECM has a unique hierarchical anisotropic structure from nano- to macro-scale (Rho et al., 1998). The macro structure can be divided into cortical or cancellous bone, which microstructurally consists of harversian systems and trabecular respectively (Weiner and Traub, 1992). The nanostructure is composed of fibrillar collagen, embedded mineral and non-collagenous proteins including osteopontin, osteocalcin, osteonectin and bone sialoprotein, which contribute to the orientation and size of the HAP crystals (Nakano et al., 2002; Rho et al., 1998); consequently, replicating this complex hierarchically organised structure in order to effectively provide the diverse mechanical, biological and chemical functions of bone ECM is a significant challenge for tissue engineering and regenerative medicine based strategies. The size and distribution of pores within biomaterial scaffolds is crucial in dictating cellular behaviour, infiltration and distribution as well as the diffusion of nutrients and waste products (Annabi et al., 2010). The incorporation of cells in the liquid state prior to gelation also ensures that the interconnecting porous network is able to assemble around the cells. The increase in structural density and reduction in pore size observed in hMSC hydrogels with $0.5 \mathrm{mg} / \mathrm{mL}$ HAPna is likely to be due to both a significant decrease in the hydration degree, where hMSC were incorporated into hydrogel scaffolds, in comparison to acellular controls and hMSC depositing matrix within pores, both of which contribute to the increase in mechanical properties observed where hMSCs were added into hydrogel scaffolds in comparison to acellular controls.

The composition of the matrix was assessed histologically and found to consist of collagen, identified by Masson's trichrome and calcium confirmed by alizarin red staining. Mineralisation was further supported by the identification of a calcium and phosphate peak, observed using EDX spectra. Histologically, cells were also shown to be producing proteoglycans as observed by Alcian Blue staining; however, increased matrix staining intensity was also observed in acellular controls, thus the increase in staining intensity could be due to an increase in background staining. Unfortunately, biochemical quantification of matrix composition was not possible as the hydrogel system was non-digestible to enable release of factors for analysis, hence semi quantification was performed on histological analysis. Furthermore, examination by immunohistochemistry identified collagen type I and increased expression and deposition of osteocalcin and osteopontin throughout the 6 week culture period. The increase in matrix deposition was also supported by a significant increase in the dry mass of hMSC hydrogel scaffolds after 6 weeks in culture containing $0.5 \mathrm{mg} / \mathrm{mL}$ HAPna.

A second contributing factor to the significant decrease in pore size may also be due to the hydration degree of the hydrogel scaffolds. The hydration degree of biomaterial scaffolds is a crucial indicator of cellular infiltration and important in the diffusion of nutrients and waste products (Annabi et al., 2010). The significant reduction in hydration degree is likely due to cell contraction forces when the intracellular tension is exerted to the ECM through focal adhesions, resulting in physical links between the ECM and the actin cytoskeleton (Li and Wang, 2010). These forces play an essential role-enabling cell migration (Pourati et al., 1998), mechanical sensing and controlling cell shape and tensional homeostasis (Beningo and Wang, 2002; Brown et al., 1998). This phenomenon has been replicated elsewhere where cells were shown to contract and reduce the size of collagen matrix in vitro (Ehrlich and Rajaratnam, 1990). A significant decrease in the hydration degree of hMSC hydrogel constructs with $1.0 \mathrm{mg} / \mathrm{mL}$ HAPna was observed from $48 \mathrm{~h}$ to 2 weeks, despite a decrease in metabolic cell activity, indicating cytotoxicity, observed in these constructs up to $7 \mathrm{~d}$. No significant difference in the hydration degree of hMSC hydrogel constructs with $1.0 \mathrm{mg} / \mathrm{mL}$ HAPna was observed from 2 to 6 weeks in culture, which could suggest that that after 2 weeks cells are mainly dead. It is possible that viable cells, which were present in the initial days of culture, were able to constrict the size of the construct with resultant loss in water content; this reflects the substantial reduction in hydration degree which is observed from $48 \mathrm{~h}$ to 1 week in culture. Following the initial loss in water, it is likely that re-swelling of the hydrogel to restore the hydration degree, does not take place regardless of whether the cells are alive or dead, since the hydrogel is being cultured at the gelation temperature $\left(37^{\circ} \mathrm{C}\right)$.

Compositionally, we have shown that the L-pNIPAMco-DMAc hydrogel supplemented optimally with $0.5 \mathrm{mg} /$ mL HAPna induces matrix synthesis, consisting of collagen and non-collagenous proteins such as osteocalcin and osteopontin, together with increased deposition of calcium mimicking native bone matrix. Despite this, structural regeneration of bone ECM in vitro which replicates the native anisotropic structure represents a significant challenge (Ishimoto et al., 2013, Nakano et al., 2002). Patterning of ECM deposition can be influenced by cell orientation (Wang et al., 2003), anisotropic mechanical environment (Matsugaki et al., 2013) and in response to external stimuli (Matsugaki et al., 2015), thus it is hypothesised that regeneration of bone matrix in vitro which consists of the correct nanostructural components will only truly replicate the complex hierarchical structure of bone in vivo where cells are subjected to the native biological, chemical and physical microenvironmental cues which induces specified cellular and tissue arrangement. 


\section{Induction of osteogenic differentiation}

The development of a biomaterial scaffold that promotes repair and regeneration of bone ECM is reliant on the bioactivity of the biomaterial and its ability to promote and facilitate osteogenic activity with consequential mineralisation. Bone tissue forms by eventual differentiation of MSCs to osteoblasts that synthesise and deposit collagen type I, the main ECM component of bone matrix (Shapiro, 2008). In the current study the ability of $0.5 \mathrm{mg} / \mathrm{mL}$ HAPna loaded L-pNIPAM-co-DMAc hydrogels to induce osteogenic differentiation of bone marrow derived hMSCs, without the use of osteogenic growth factors was assessed immunohistochemically. The ubiquitous expression of Collagen type $\mathrm{X}$ in hMSCS suggests evidence of predifferentiation; however, bone marrow derived MSCs have been shown to express collagen type $\mathrm{X}$ (Jacenko et al., 1996; Mwale et al., 2006); thus, collagen type X cannot be considered as a definitive marker of hypertrophic chondrocytes. Runx 2 is regarded as the fundamental transcription factor required for osteogenic differentiation of MSCs to fully differentiated osteoblasts, resulting in the up-regulation of osteogenic proteins including collagen type I, osteopontin and osteocalcin (Ducy et al., 1997). The increased Runx 2 expression, followed by a significant down regulation after 2 weeks in culture, is typical of Runx 2 expression seen during differentiation of pre-osteoblasts to mature osteoblasts (Komori, 2010; Maruyama et al., 2007). The early bone matrix marker, collagen type I, as well as osteopontin and osteocalcin, two late phase markers of mature osteogenesis, which have cell and calcium binding domains (Lian and Stein, 1992) and have been shown to be upregulated following the onset of mineralisation (Sodek and Cheifetz, 2000), were highly expressed by hMSCs following 6 weeks in culture, after incorporation into $0.5 \mathrm{mg} / \mathrm{mL}$ HAPna loaded hydrogel nanocomposite scaffold. Collagen type I was found to be highly expressed by hMSC prior to hydrogel incorporation which could suggest pre-differentiation of the cells since the hMSCs are derived from bone marrow; however, the percentage of hMSCs expressing late phase osteogenic protein markers (osteopontin and osteocalcin) were only significantly increased following incorporation in $0.5 \mathrm{mg} / \mathrm{mL}$ HAPna containing L-pNIPAM-co-DMAc hydrogel constructs; thus demonstrating the bioactive properties of this hydrogel system with differentiation of MSCs into mature osteoblasts capable of depositing a bone like matrix rich in calcium, demonstrated by Alizarin red staining and the formation of possible osteoid nodules, determined by the identification of calcium and phosphate peaks, following 6 weeks in culture, by EDX spectra. Whereas expression of chondrogenic markers, aggrecan and collagen type II, remained unchanged or were significantly decreased - thus confirming the osteogenic phenotype of MSCs incorporated into hydrogel constructs containing $0.5 \mathrm{mg} / \mathrm{mL}$ HAPna. The viability and osteogenic differentiation of late passage hMSCs within L-pNIPAMco-DMAc hydrogel constructs loaded with $0.5 \mathrm{mg} /$ mL HAPna, is encouraging, since stem cells extracted from elderly patients, whom degenerative bone diseases typically afflict, have been shown to have a reduced capacity for proliferation and differentiation (Stolzing et al., 2008). However, the osteogenic differentiation of hMSC demonstrated here was performed with one donor at passage nine; therefore, caution in interpreting these results should be considered.

A variety of bioactive injectable hydrogel scaffolds have been reported; however, many systems preclude the incorporation of cells in the liquid state as they require co-injection with cross linking agents (Halacheva et al., 2014; Lally et al., 2007; Saunders et al., 2007; Shin et al., 2003). Other systems are too viscous for injection through fine-bore needles, which may limit the potential number of bone repair clinical applications and result in further damage to the target site (Michalek et al., 2010; Nassr et al., 2009). Other hydrogels, alternative to pNIPAM/HAP hydrogels for MSC delivery, have been reported; however, the viability of cells incorporated prior to gelation has not always been assessed (Couto et al., 2009) or the use of growth factors has been necessary to induce osteogenesis (Kim et al., 2007; Martínez-Sanz et al., 2011; Kim et al., 2007; Kim et al., 2011; Liao et al., 2011; Martínez-Sanz et al., 2011; Na et al., 2007). The L-pNIPAM-co-DMAc hydrogel system described here is processed in a novel manner, whereby synthesising pNIPAM at $80{ }^{\circ} \mathrm{C}$ (i.e. above the gelation temperature) on the surface of dispersed Laponite platelets, we are able to produce a colloidal nanosuspension that remains a low viscosity liquid if held above the gelation temperature $\left(37.1 \pm 0.16^{\circ} \mathrm{C}\right)$. Upon cooling, the pNIPAM chains convert from the globule to the coil conformation, become entangled and form a gel, supported by physical crosslinks with the Laponite ${ }^{\circledR}$ platelets, that does not melt upon reheating. This is indeed unlike other pNIPAM based hydrogels, and generates a hydrogel with lower viscosity than previously reported systems, which has the potential to fill small cracks, fissures and voids within the bone. In addition, growth factor free approaches to injectable composite hydrogels for use in bone augmentation have been limited; recently, Xavier et al. (2015) reported nanocomposite hydrogels capable of promoting osteogenesis in the absence of osteoconductive factors; however, the scaffold fabrication technique involved the use of photo crosslinking which raises safety concerns regarding UV exposure not only to implanted cells but also to surrounding tissues during delivery and precludes the use of minimally invasive techniques for deeper tissues (Xavier et al., 2015).

The current study utilised a bioceramic copolymer nanocomposite hydrogel loaded with HAPna, which is cytocompatible in the liquid state and requires no clean up or further purification, has a low viscosity sufficient to facilitate injection through a fine needle (26 gauge) prior to gelation at body temperature $\left(37^{\circ} \mathrm{C}\right)$ and has excellent osteoconductive properties providing a microenvironment that influences the differentiation fate of MSCs with induced expression of both early and late phase osteogenic proteins and formation of a mineralised matrix without the need for additional osteogenic inducing factors. The osteogenic inductive properties of this hydrogel system preclude the need for additional bioactive factors which will reduce regulatory requirements and clinical costs thus making such a system more favourable for therapeutic application. Future investigations should be conducted to 
assess the osteogenic inductive properties of this hydrogel with MSCs extracted from a large cohort of human patients to determine patient variability and age of patients which can be utilised.

\section{Conclusion}

The current study used a HAPna loaded L-pNIPAM-coDMAc nanocomposite hydrogel to induce osteogenic differentiation of hMSCs and thus regenerate a mineralised matrix. Although there are many studies using HAP biomaterials for bone regeneration, this synthetic hydrogel addresses several clinical requirements in one biomaterial. It is cytocompatible in the liquid state and thus enables safe and homogenous encapsulation of cells and HAPna, the fabrication technique utilised does not require additional chemicals to be added for gelation or clean up and the hydrogel undergoes gelation at body temperature. Furthermore, following cellular incorporation, the hydrogel containing HAPna, was capable of inducing osteogenic differentiation of MSCs without the addition of growth factors. This has key implications because such a therapeutic strategy could utilise the patient's own MSCs and be injected directly into the target site without the need for external biological manipulation, thus reducing treatment costs, simplifying the treatment strategy regulatory requirements and potentially providing safe and efficacious repair and regeneration of lost bone.

\section{Acknowledgements}

We would like to offer kind thanks to Sheffield Hallam University staff member P. Allender, at the Materials and Engineering Research Institute, for help with the use of the energy dispersive X-ray (EDX) analysis software. The authors would like to thank the Biomolecular Sciences Research Centre, Sheffield Hallam University for $\mathrm{PhD}$ studentship and EPSRC (EP/H000275/1 + EP/I016473/1) for funding.

\section{Author contributions}

AAT performed all laboratory work, data analysis and statistical analysis, contributed to study design and drafted the manuscript. SC contributed technical expertise to SEM and critically revised the manuscript. CS contributed to study design, aided in analysis of the data, secured funding and critically revised the manuscript. CLLM conceived of the study, participated in its design and coordination, aided in the analysis of data, secured funding and critically revised the manuscript. All authors read and approved the final manuscript.

\section{References}

Annabi N, Nichol JW, Zhong X, Ji C, Koshy S, Khademhosseini A, Dehghani F (2010) Controlling the porosity and microarchitecture of hydrogels for tissue engineering. Tissue Eng Part B Rev 16: 371-383.
Beningo KA, Wang YL (2002) Flexible substrata for the detection of cellular traction forces. Trends Cell Biol 12: 79-84.

Benoit DS, Schwartz MP, Durney AR, Anseth KS (2008) Small functional groups for controlled differentiation of hydrogel-encapsulated human mesenchymal stem cells. NatMater 7: 816-823.

Boyes VL, Sammon C, Lemaitre C, Breen C (2012a) Precipitation polymerisation yields novel biologically safe fully reacted thermally responsive injectable hydrogel with potential for regenerative medicine. Patent i.d:20140219973A1.

Boyes VL, Sammon C, Lemaitre C, Breen C (2012b). Composite hydrogel-clay particles. Sheffield Hallam University. Faculty of Arts, Computing, Engineering and Sciences. Thesis no.27578.

Brown RA, Prajapati R, McGrouther DA, Yannas IV, Eastwood M (1998) Tensional homeostasis in dermal fibroblasts: mechanical responses to mechanical loading in three-dimensional substrates. J Cell Physiol 175: 323-332.

Buwalda SJ, Boere KW, Dijkstra PJ, Feijen J, Vermonden T, Hennink WE (2014) Hydrogels in a historical perspective: From simple networks to smart materials. J Control Release 190: 254-273.

Choi K, Kuhn JL, Ciarelli MJ, Goldstein SA (1990) The elastic moduli of human subchondral, trabecular, and cortical bone tissue and the size-dependency of cortical bone modulus. J Biomech 23: 1103-1113.

Couto DS, Hong Z, Mano JF (2009) Development of bioactive and biodegradable chitosan-based injectable systems containing bioactive glass nanoparticles. Acta Biomater 5: 115-123.

D'Este M, Eglin D (2013) Hydrogels in calcium phosphate moldable and injectable bone substitutes: Sticky excipients or advanced 3-D carriers? Acta Biomater 9: 5421-5430.

Dhivya S, Saravanan S, Sastry TP, Selvamurugan N (2015) Nanohydroxyapatite-reinforced chitosan composite hydrogel for bone tissue repair in vitro and in vivo. $\mathrm{J}$ Nanobiotechnology 13: 40.

Discher DE, Janmey P, Wang YL (2005) Tissue cells feel and respond to the stiffness of their substrate. Science 310: 1139-1143.

Ducy P, Zhang R, Geoffroy V, Ridall AL, Karsenty G (1997) Osf2/Cbfa1: a transcriptional activator of osteoblast differentiation. Cell 89: 747-754.

Ehrlich HP, Rajaratnam JB (1990) Cell locomotion forces versus cell contraction forces for collagen lattice contraction: an in vitro model of wound contraction. Tissue Cell 22: 407-417.

Furlong RJ, Osborn JF (1991) Fixation of hip prostheses by hydroxyapatite ceramic coatings. J Bone Joint Surg Br 73: 741-745.

Geckil H, Xu F, Zhang X, Moon S, Demirci U (2010) Engineering hydrogels as extracellular matrix mimics. Nanomedicine 5: 469-484.

Gkioni K, Leeuwenburgh SC, Douglas TE, Mikos AG, Jansen JA (2010) Mineralization of hydrogels for bone regeneration. Tissue Eng Part B Rev 16: 577-585.

Goulet JA, Senunas LE, DeSilva GL, Greenfield ML (1997) Autogenous iliac crest bone graft: complications 
and functional assessment. Clin Orthop Relat Res 339: 76-81.

Halacheva SS, Adlam DJ, Hendow EK, Freemont TJ, Hoyland J, Saunders BR (2014) Injectable biocompatible and biodegradable $\mathrm{pH}$-responsive hollow particle gels containing poly (acrylic acid): the effect of copolymer composition on gel properties. Biomacromolecules 15: 1814-1827.

Haraguchi K, Takehisa T, Ebato M (2006) Control of cell cultivation and cell sheet detachment on the surface of polymer/clay nanocomposite hydrogels. Biomacromolecules 7: 3267-3275.

Ishimoto T, Nakano T, Umakoshi Y, Yamamoto M, Tabata Y (2013) Degree of biological apatite c-axis orientation rather than bone mineral density controls mechanical function in bone regenerated using recombinant bone morphogenetic protein-2. J Bone Miner Res 28: 11701179 .

Isikli C, Hasirci V, Hasirci N (2012) Development of porous chitosan-gelatin/hydroxyapatite composite scaffolds for hard tissue-engineering applications. J Tissue Eng Regen Med 6: 135-143.

Jacenko O, Ito S, Olsen BR (1996) Skeletal and hematopoietic defects in mice transgenic for collagen $\mathrm{X}$. Ann N Y Acad Sci 785: 278-280.

Jiang Y, Jahagirdar BN, Reinhardt RL, Schwartz RE, Keene CD, Ortiz-Gonzalez XR, Reyes M, Lenvik T, Lund T, Blackstad M, Du J, Aldrich S, Lisberg A, Low WC, Largaespada DA, Verfaillie CM (2002) Pluripotency of mesenchymal stem cells derived from adult marrow. Nature 418: 41-49.

Kim J, Kim IS, Cho TH, Lee KB, Hwang SJ, Tae G, Noh I, Lee SH, Park Y, Sun K (2007) Bone regeneration using hyaluronic acid-based hydrogel with bone morphogenic protein-2 and human mesenchymal stem cells. Biomaterials 28: 1830-1837.

Kim S, Tsao H, Kang Y, Young DA, Sen M, Wenke JC, Yang Y (2011) In vitro evaluation of an injectable chitosan gel for sustained local delivery of BMP-2 for osteoblastic differentiation. J Biomed Mater Res B Appl Biomater 99: 380-390.

Komori T (2010) Regulation of bone development and extracellular matrix protein genes by RUNX2. Cell Tissue Res 339: 189-195.

Kraus KH, Kirker-Head C (2006) Mesenchymal stem cells and bone regeneration. Vet Surg 35: 232-242.

Kumar D, Gerges I, Tamplenizza M, Lenardi C, Forsyth NR, Liu Y (2014) Three-dimensional hypoxic culture of human mesenchymal stem cells encapsulated in a photocurable, biodegradable polymer hydrogel: A potential injectable cellular product for nucleus pulposus regeneration. Acta Biomaterialia 10: 3463-3474.

Lally S, Mackenzie P, LeMaitre CL, Freemont TJ, Saunders BR (2007) Microgel particles containing methacrylic acid: pH-triggered swelling behaviour and potential for biomaterial application. J Colloid Interface Sci 316: 367-375.

Le Maitre CL, Freemont AJ, Hoyland JA (2005) The role of interleukin-1 in the pathogenesis of human intervertebral disc degeneration. Arthritis Res Ther 7: R732-R745.
Lei Y, Gojgini S, Lam J, Segura T (2011) The spreading, migration and proliferation of mouse mesenchymal stem cells cultured inside hyaluronic acid hydrogels. Biomaterials 32: 39-47.

Li B, Wang JH (2010) Application of sensing techniques to cellular force measurement. Sensors 10: 9948-9962.

Lian JB, Stein GS (1992) Concepts of osteoblast growth and differentiation: basis for modulation of bone cell development and tissue formation. Crit Rev Oral Biol Med 3: 269-305.

Liao HT, Chen CT, Chen JP (2011) Osteogenic differentiation and ectopic bone formation of canine bone marrow-derived mesenchymal stem cells in injectable thermo-responsive polymer hydrogel. Tissue Eng Part C Methods 17: 1139-1149.

Liu Q, De Wijn JR, Van Blitterswijk CA (1997) Nano-apatite/polymer composites: mechanical and physicochemical characteristics. Biomaterials 18: 12631270.

Lutolf M, Hubbell J (2005) Synthetic biomaterials as instructive extracellular microenvironments for morphogenesis in tissue engineering. Nat Biotechnol 23: 47-55.

Martínez-Sanz E, Ossipov DA, Hilborn J, Larsson S, Jonsson KB, Varghese OP (2011) Bone reservoir: Injectable hyaluronic acid hydrogel for minimal invasive bone augmentation. J ControlRelease 152: 232-240.

Maruyama Z, Yoshida CA, Furuichi T, Amizuka N, Ito M, Fukuyama R, Miyazaki T, Kitaura H, Nakamura K, Fujita T, Kanatani N, Moriishi T, Yamana K, Liu W, Kawaguchi H, Nakamura, Komori T (2007) Runx2 determines bone maturity and turnover rate in postnatal bone development and is involved in bone loss in estrogen deficiency. Dev Dyn 236: 1876-1890.

Matsugaki A, Aramoto G, Ninomiya T, Sawada H, Hata S, Nakano T (2015) Abnormal arrangement of a collagen/ apatite extracellular matrix orthogonal to osteoblast alignment is constructed by a nanoscale periodic surface structure. Biomaterials 37: 134-143.

Matsugaki A, Fujiwara N, Nakano T (2013) Continuous cyclic stretch induces osteoblast alignment and formation of anisotropic collagen fiber matrix. Acta Biomater 9: (7) 7227-7235.

Michalek AJ, Buckley MR, Bonassar LJ, Cohen I, Iatridis JC (2010) The effects of needle puncture injury on microscale shear strain in the intervertebral disc annulus fibrosus. Spine J 10: 1098-1105.

Mistry AS, Mikos AG (2005) Tissue engineering strategies for bone regeneration. Adv Biochem Eng Biotechnol 94:1-22.

Mwale F, Stachura D, Roughley P, Antoniou J (2006) Limitations of using aggrecan and type $\mathrm{X}$ collagen as markers of chondrogenesis in mesenchymal stem cell differentiation. J Orthop Res 24: 1791-1798.

Na K, Kim SW, Sun BK, Woo DG, Yang HN, Chung HM, Park KH (2007) Osteogenic differentiation of rabbit mesenchymal stem cells in thermo-reversible hydrogel constructs containing hydroxyapatite and bone morphogenic protein-2 (BMP-2). Biomaterials 28: 26312637. 
Nakano T, Kaibara K, Tabata Y, Nagata N, Enomoto S, Marukawa E, Umakoshi Y (2002) Unique alignment and texture of biological apatite crystallites in typical calcified tissues analyzed by microbeam X-ray diffractometer system. Bone 31: 479-487.

Nassr A, Lee JY, Bashir RS, Rihn JA, Eck JC, Kang JD, Lim MR (2009) Does incorrect level needle localization during anterior cervical discectomy and fusion lead to accelerated disc degeneration? Spine (Phila Pa 1976) 34: 189-192.

Nilsson KG, Kärrholm J, Carlsson L, Dalén T (1999) Hydroxyapatite coating versus cemented fixation of the tibial component in total knee arthroplasty: prospective randomized comparison of hydroxyapatite-coated and cemented tibial components with 5-year follow-up using radiostereometry. J Arthroplasty 14: 9-20.

Owen SC, Shoichet MS (2010) Design of threedimensional biomimetic scaffolds. J Biomed Mater Res A 94: 1321-1331.

Pan Y, Xiong D, Gao F (2008) Viscoelastic behavior of nano-hydroxyapatite reinforced poly (vinyl alcohol) gel biocomposites as an articular cartilage. J Mater Sci Mater Med 19: 1963-1969.

Park H, Temenoff JS, Tabata Y, Caplan AI, Mikos AG (2007) Injectable biodegradable hydrogel composites for rabbit marrow mesenchymal stem cell and growth factor delivery for cartilage tissue engineering. Biomaterials 28: 3217-3227.

Pourati J, Maniotis A, Spiegel D, Schaffer JL, Butler JP, Fredberg JJ, Ingber DE, Stamenovic D, Wang N (1998) Is cytoskeletal tension a major determinant of cell deformability in adherent endothelial cells?. Am J Physiol 274: C1283-C1289.

Qing F, Wang Z, Hong Y, Liu M, Guo B, Luo H, Zhang X (2012) Selective effects of hydroxyapatite nanoparticles on osteosarcoma cells and osteoblasts. J Mater Sci Mater Med 23: 2245-2251.

Rea SM, Best SM, Bonfield W (2004) Bioactivity of ceramic-polymer composites with varied composition and surface topography. J Mater Sci Mater Med 15: 997-1005.

Reilly DT, Burstein AH, Frankel VH (1974) The elastic modulus for bone. J Biomech 7: 271-275.

Rho JY, Ashman RB, Turner CH (1993) Young's modulus of trabecular and cortical bone material: ultrasonic and microtensile measurements. J Biomech 26: 111-119.

Rho JY, Kuhn-Spearing L, Zioupos P (1998) Mechanical properties and the hierarchical structure of bone. Med Eng Phys 20: 92-102.

Rho J, Tsui TY, Pharr GM (1997) Elastic properties of human cortical and trabecular lamellar bone measured by nanoindentation. Biomaterials 18: 1325-1330.

Sakaguchi Y, Sekiya I, Yagishita K, Muneta T (2005) Comparison of human stem cells derived from various mesenchymal tissues: superiority of synovium as a cell source. Arthritis Rheum 52: 2521-2529.

Saunders JM, Tong T, Le Maitre CL, Freemont TJ, Saunders BR (2007) A study of pH-responsive microgel dispersions: from fluid-to-gel transitions to mechanical property restoration for load-bearing tissue. Soft Matter 3: 486-494.
Sen M, Miclau T (2007) Autologous iliac crest bone graft: should it still be the gold standard for treating nonunions?. Injury 38: S75-S80.

Shapiro F (2008) Bone development and its relation to fracture repair. The role of mesenchymal osteoblasts and surface osteoblasts. Eur Cell Mater 15: 53-76.

Shin H, Temenoff JS, Mikos AG (2003) In vitro cytotoxicity of unsaturated oligo [poly (ethylene glycol) fumarate] macromers and their cross-linked hydrogels. Biomacromolecules 4: 552-560.

Sinha A, Das G, Kumar Sharma B, Prabahan Roy R, Kumar Pramanick A, Nayar S (2007) Poly (vinyl alcohol)hydroxyapatite biomimetic scaffold for tissue regeneration. Materials Science and Engineering: C 27: 70-74.

Sodek J, Cheifetz S (2000) Molecular regulation of osteogenesis. Bone engineering 1: 31-43.

Stein GS, Lian JB, Van Wijnen AJ, Stein JL, Montecino M, Javed A, Zaidi SK, Young DW, Choi J, Pockwinse SM (2004) Runx2 control of organization, assembly and activity of the regulatory machinery for skeletal gene expression. Oncogene 23: 4315-4329.

Stolzing A, Jones E, McGonagle D, Scutt A (2008) Age-related changes in human bone marrow-derived mesenchymal stem cells: consequences for cell therapies. Mech Ageing Dev 129: 163-173.

Sun JS, Tsuang YH, Liao CJ, Liu HC, Hang YS, Lin FH (1997) The effects of calcium phosphate particles on the growth of osteoblasts. J Biomed Mater Res 37: 324-334.

Thorpe AA, Boyes V, Sammon C, Le Maitre C (2016) Thermally triggered injectable hydrogel, which induces mesenchymal stem cell differentiation to nucleus pulposus cells: Potential for regeneration of the intervertebral disc. Acta Biomater 36: 99-111.

Trappmann B, Gautrot JE, Connelly JT, Strange DG, Li Y, Oyen ML, Cohen Stuart MA, Boehm H, Li B, Vogel V, Spatz JP, Watt FM, Huck WT (2012) Extracellular-matrix tethering regulates stem-cell fate. Nat Mater 11: 642-649.

Venugopal J, Prabhakaran MP, Zhang Y, Low S, Choon AT, Ramakrishna S (2010) Biomimetic hydroxyapatitecontaining composite nanofibrous substrates for bone tissue engineering. Philos Trans A Math Phys Eng Sci 368: 2065-2081.

Wang JH, Jia F, Gilbert TW, Woo SL (2003) Cell orientation determines the alignment of cell-produced collagenous matrix. J Biomech 36: 97-102.

Wang LS, Du C, Chung JE, Kurisawa M (2012) Enzymatically cross-linked gelatin-phenol hydrogels with a broader stiffness range for osteogenic differentiation of human mesenchymal stem cells. Acta Biomater 8: 18261837.

Wei J, He P, Liu A, Chen X, Wang X, Jing X (2009) Surface Modification of Hydroxyapatite Nanoparticles with Thermal-Responsive PNIPAM by ATRP. Macromol Biosci 9:1237-1246.

Weiner S, Traub W (1992) Bone structure: from angstroms to microns. FASEB J 6: 879-885.

Willenbacher N (1996) Unusual thixotropic properties of aqueous dispersions of laponite RD. J Colloid Interface Sci 182: 501-510.

Xavier JR, Thakur T, Desai P, Jaiswal MK, Sears N, Cosgriff-Hernandez E, Kaunas R, Gaharwar AK (2015) 
Bioactive nanoengineered hydrogels for bone tissue engineering: a growth-factor-free approach. ACS Nano 9: 3109-3118.

Yoshimura H, Muneta T, Nimura A, Yokoyama A, Koga H, Sekiya I (2007) Comparison of rat mesenchymal stem cells derived from bone marrow, synovium, periosteum, adipose tissue, and muscle. Cell Tissue Res 327: 449-462.

Zhao F, Grayson WL, Ma T, Bunnell B, Lu WW (2006) Effects of hydroxyapatite in 3-D chitosan-gelatin polymer network on human mesenchymal stem cell construct development. Biomaterials 27: 1859-1867.

\section{Discussion with Reviewers}

Reviewer I: As this hydrogel is non-degradable and does not really prone host cells migration and tissue infiltration, we can question if, following implantation, the angiogenesis will be fast enough to create a functional bone tissue.

Authors: Within bone tissue, cells reside in close proximity to blood vessels that crucially supply tissues with oxygen and nutrients and facilitate the removal of carbon dioxide as well as other waste products; thus the regeneration of a functional bone matrix is reliant on the efficient vascularisation of the injected L-pNIPAM-co-DMAc hydrogel reported in this study. Chiu et al., 2011 demonstrated that scaffold pore size influences neovascularisation with pores $(25-50 \mu \mathrm{m})$ limiting neovascularisation to the external surface of the hydrogel (Chiu et al., 2011). The synthetic route employed in this study uniquely results in a 3-dimensional polymeric network, which is fixed in terms of its state but is simultaneously able to facilitate polymer chain displacement so that cells are able to migrate through the hydrogel, independent of pore size; thus despite the hydrogel being non-degradable it does facilitate cellular migration. Furthermore, we have demonstrated that HDMEC cells, which are capable of neovascularisation, were able to migrate through the entire length of a $10 \mathrm{~mm}$ thick pre-set hydrogel construct following 2 weeks in culture (Fig. DWR1). It is envisaged that this hydrogel will be most suited as a support scaffold to deliver regenerative cells for bone repair applications such as small non-union fractures, artificial joint fixation and osteoporosis as opposed to large defects; thus it is likely that the distance, and resultant time taken, for cell migration into the hydrogel scaffold in vivo to induce vascularisation will be sufficient to facilitate the survival of transplanted cells and functional integration of the scaffold with surrounding bone tissue.

Reviewer I: The new Fig. DWR1 does not really bring any clear supplementary information. The green autofluorescence background of the gel is really high and we observe only scarce clusters of cell agglomerated altogether. In fact, those cells do not exhibit 'migrating phenotype' as illustrated by the schematics on the left side of this figure. From my point of view, this figure does not persuade ECM readers to the suitability of this hydrogel to be vascularised following implantation.
Authors: Fig. DWR1 demonstrates a cross section of hydrogel following 2 weeks after loading HDMEC cells on top of pre-set $10 \mathrm{~mm}$ thick hydrogel constructs. Due to the autofluorescence of the hydrogel, which is unfortunately unavoidable, the migrating phenotype of cells cannot be accurately visualised. Despite this, cellular bodies can be visualised at the surface of the hydrogel, and within the deeper layers; therefore, we feel HDMEC cells must have migrated through the material. We agree that this alone does not provide sufficient evidence to suggest that vascularisation of the hydrogel in vivo would be efficient enough to enable integration of the scaffold and subsequent repair of surrounding bone tissue; however, this does demonstrate that HDMEC cells, which are capable of neovascularisation, are able to migrate through the hydrogel; future studies are required to further investigate the vascularisation of the hydrogel, which is essential to facilitate regeneration of a functional bone matrix. We have ensured this is now conveyed in our response.

Reviewer III: The authors present an interesting composite biomaterial with an atypical gelation mechanism, which is shown to support MSC differentiation to bone cells in vitro. However, the material is non-degradable. Do the authors think that this could be a limitation?

Authors: We hypothesise that the non-biodegradable nature of the L-pNIPAM-co-DMAc hydrogel with HAPna, developed here, would not be a limitation since it reduces issues associated with scaffold degradation such as the toxicity of degradation products as well as the challenge of matching scaffold degradation with matrix regeneration, which inevitably will be patient dependent. It is envisaged that the non-biodegradable hydrogel will provide long term scaffold support whilst the newly synthesised bone tissue will undergo natural tissue remodelling to regenerate a fully integrated and functional bone/scaffold matrix; however, future in-vivo investigations are essential to determine the long term fate of this hydrogel as a non-biodegradable cell carrier scaffold.

Reviewer III: The authors highlighted that the use of a nonbiodegradable and injectable system is more advantageous than the current therapeutic alternatives because it enables the easy application to micro fissures within the bone, and avoids loss of mechanical performance seen during scaffold degradation in other biodegradable systems. Taking into account the classical approach in which scaffold degrades allowing cells to colonize and to form new tissue, I would suggest considering this injectable system as a carrier, to support cell differentiation, rather than a scaffold. It is still unclear how this non-biodegradable construct would facilitate bone tissue regeneration as it remains at the implant site. The authors should further explain the final application of this material.

Authors: The cytocompatibility and low viscosity of the L-pNIPAM-co-DMAc hydrogel, developed here, enables the delivery of regenerative cells by minimally invasive injection followed by in-situ gelation to assist in the natural repair and regeneration of bone matrix. Reviewer 3 is correct that an important application of this hydrogel is that it can be used as an injectable cell carrier to promote 

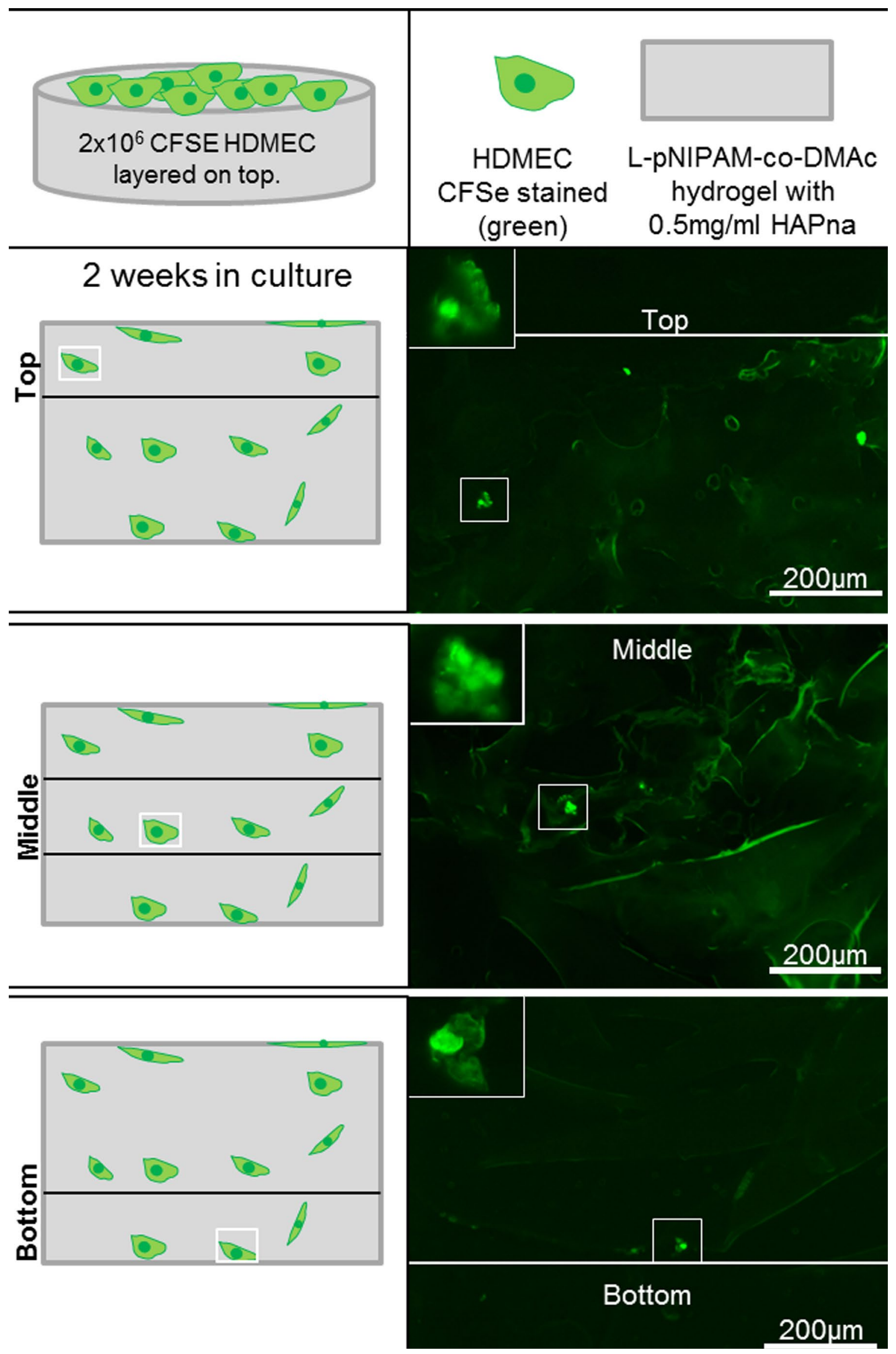

Fig. DWR1. Human Dermal Microvascular Endothelial Cells (HDMEC) $\left(2 \times 10^{6}\right.$ cells $\left./ \mathrm{mL}\right)$, labelled with a fluorescent CFSe stain for tracking, layered on top of $10 \mathrm{~mm}$ thick pre-set L-pNIPAM-co-DMAc hydrogel constructs with $0.5 \mathrm{mg} /$ mL HAPna and cultured for 2 weeks. Representative images of HDMEC cells from the top, middle and bottom of hydrogel constructs; demonstrating cell migration through the entire length of the hydrogel. 
osteogenic cellular differentiation of transplanted stem cells and thus regenerate bone matrix. The low viscosity nature of this system also enables the liquid hydrogel to fill micro and macro fractures prior to solidification at $37{ }^{\circ} \mathrm{C}$. Within small bone defects, we hypothesise that the hydrogel will provide a scaffold between adjacent surfaces of native bone tissue, which will provide initial mechanical support, facilitate the migration of native cells to aid tissue integration as well as promote osteogenic differentiation of transplanted cells to regenerate a functionally integrated bone matrix. We envisage that this non-biodegradable hydrogel scaffold will provide long term support, whilst the regenerated matrix within and surrounding the hydrogel undergoes natural tissue remodelling. The non-biodegradable properties of this hydrogel avoid issues associated with scaffold degradation such as toxicity of degradation products as well as the challenge of matching scaffold degradation with matrix regeneration which inevitably will be patient dependant. For the repair of small bone defects, as well as clinical cases of osteoporosis, the L-pNIPAM-co-DMAc hydrogel could provide the beneficial properties of both a carrier and a scaffold; however, for larger bone defects the hydrogel is likely to be mechanically insufficient and thus may be applied as a cell delivery scaffold, in combination with an additional support scaffold, to promote the regeneration and integration of bone tissue. The promising results obtained here in vitro suggest that this L-pNIPAM-coDMAc hydrogel could utilise the patient's own MSCs to regenerate bone tissue, without the need for external biological manipulation; however, future in vivo studies are essential to fully elucidate the long term fate of this hydrogel within bone tissue.

\section{Additional Reference}

Chiu YC, Cheng MH, Engel H, Kao SW, Larson JC, Gupta S, Brey EM (2011) The role of pore size on vascularization and tissue remodeling in PEG hydrogels. Biomaterials 32: 6045-6051.

Editor's Note: Scientific Editor in charge of the paper: Mauro Alini. 